\title{
UTILIZAÇÃO DA VIDEOGRAFIA AÉREA NA DETECÇÃO DE ÁREAS COM DEFICIÊNCIAS NUTRICIONAIS EM PLANTIOS DE EUCALIPTO
}

\section{PAULO POMPERMAYER NETO}

\begin{abstract}
Dissertação apresentada à Escola Superior de Agricultura "Luiz de Queiroz", Universidade de São Paulo, para obtenção do título de Mestre em Ciências, Área de Concentração: Ciências Florestais.
\end{abstract}

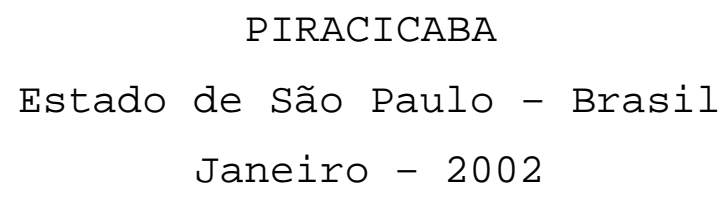




\title{
UTILIZAÇÃO DA VIDEOGRAFIA AÉREA NA DETECÇÃO DE ÁREAS COM DEFICIÊNCIAS NUTRICIONAIS EM PLANTIOS DE EUCALIPTO
}

\author{
PAULO POMPERMAYER NETO \\ Engenheiro Florestal \\ Orientador: Prof. Dr. HILTON THADEU ZARATE DO COUTO \\ Dissertação apresentada à Escola Superior \\ de Agricultura "Luiz de Queiroz", \\ Universidade de São Paulo, para obtenção do \\ título de Mestre em Ciências, Área de \\ Concentração: Ciências Florestais.

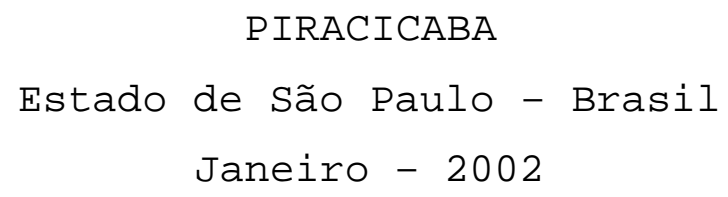


Dados Internacionais de Catalogação na Publicação (CIP) DIVISÃO DE BIBLIOTECA E DOCUMENTAÇÃO - ESALQ/USP

\author{
Pompema yer Neto, Paulo \\ Utilização da videografia aérea na detenção de áreascom \\ deficiências nutriciona is em plantios de eucalipto / Paulo Pompermayer \\ Neto. - - Pira cicaba, 2002. \\ 75 p. : il. \\ Dissertação (mestrado) - - Escola Superior de Agricultura Luiz de \\ Queiroz, 2002. \\ Bibliografia. \\ 1. Defic iência nutricional 2. Espectro 3. Euca lipto 4. Viodegra fia I. Título
}

CDD 634.9734

"Permitida a cópia total ou parcial deste documento, desde que citada a fonte - O autor" 


\section{AGRADECIMENTOS}

Aos Meus Pais, Walter e Rosa, por todo apoio e incentivo em tudo na minha vida;

À Patrícia, pelo apoio e pela grande irmã que é;

À minha querida Paula pela compreensão e carinho;

À minha avó Albertina, que sempre acreditou em mim, que continue me olhando lá de cima;

Ao meu tio Alfredo (Rico) pelo incentivo e confiança;

Ao meu Orientador, Thadeu, pela amizade, confiança e ensinamentos;

Aos professores Antônio Natal Gonçalves e Carlos A. Vettorazi pelo apoio e amizade;

Ao professor Dr. Ronaldo Ivan Silveira, do Departamento de Solos e Nutrição de Plantas, pelo apoio nas análises químicas de solo e plantas; 
Aos companheiros de vôo Jefferson, Nelson, Julio (em memória) por toda ajuda, paciência, préstimos e criatividade no desenvolvimento do sistema;

À empresa International Paper, nas pessoas de Marco Aurélio e João Comério pelo apoio e recursos na instalação e condução do experimento de campo;

Às empresas EUCATEX S/A e JARI Celulose S/A pelo apoio durante a realização do trabalho.

Aos colegas Gustavo (Beija-Flor), Fabiano (Roço), Roberta, João Dagoberto (Cobrão), Ronaldo (Boro), Edson, Luis Faria, Mário, Fábio (Nabo), Ludmila, Flaviana, André (Traveco), Roberto (Kraio), Ivo, Rogério, Ariel, Erivelto, e tantos outros que fizeram parte do cotidiano;

À CAPES, pelo apoio financeiro;

Aos professores, funcionários e amigos do Departamento de Ciências Florestais, pelo companheirismo e atenção;

Aos funcionários da biblioteca, em especial a Eliana Maria G. Sabino e Silvia M. Zinsly pela amizade e ajuda;

Ainda a todos que direta ou indiretamente colaboraram. 


\section{SUMÁRIO}

\section{Página}

RESUMO ............................... vii

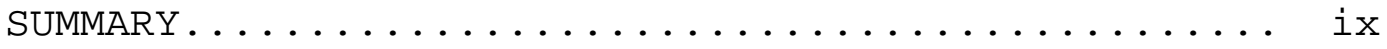

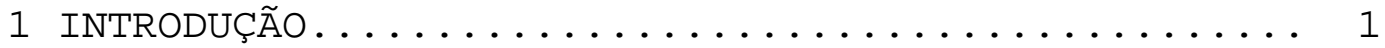

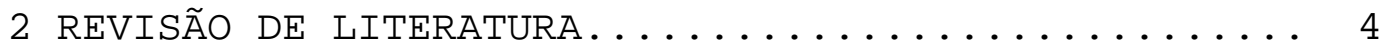

2.1 Início da utilização dos sistemas de videografia

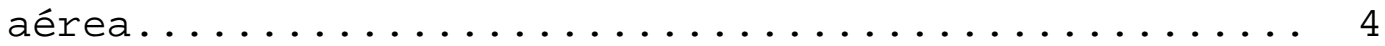

2.2 Vantagens da videografia aérea em relação a outros

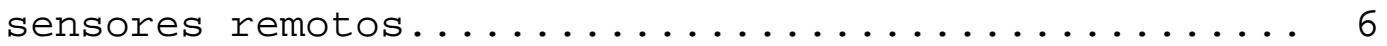

2.3 Limitações do sistema de videografia aérea...... 9 2.4 Emprego da videografia aérea em culturas....... 9 2.5 Comparação entre a videografia aérea e outros

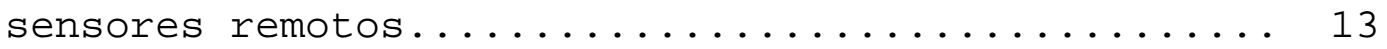

2.6 Utilização de filtros em câmeras de vídeo..... 15 2.7 Integração com sistema de informações

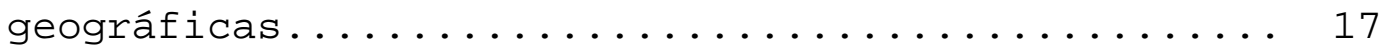

2.8 Emprego de sensores remotos em monitoramento

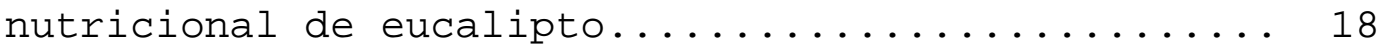

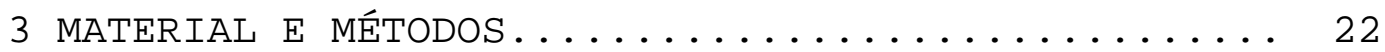

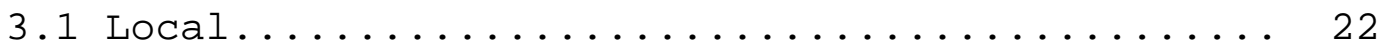

3.2 Delineamento estatístico e instalação do

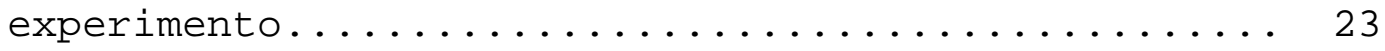

3.3 Montagem do sistema de videografia.......... 25 3.3.1 Câmeras utilizadas e sua instalação no

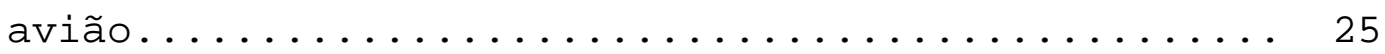


3.3 .2 Filtros..................... 28

3.4 Sobrevôo......................... 31

3.5 Captura das imagens................. 32

3.6 Análise de pixel................... 34

3.7 Dados de campo................... 36

3.7.1 Dados dendrométricos.............. 36

3.7 .2 Análises químicas.................. 37

3.8 Relação dos dados de campo com as imagens...... 38

4 RESUltados E DISCUSSÃo.................... 39

4.1 Medição dos filtros utilizados.............. 39

4.2 Análises químicas.................. 42

4.2 .1 Análise química do solo............... 42

4.2 .2 Análise química do material vegetal........ 46

4.3 Agrupamento de tratamentos conforme teor dos nutrientes nas folhas................... 50

4.4 Análises dendrométricas............... 53

4.5 Análise das imagens.................. 56

5 CONCLUSÕES........................... 64

REFERÊNCIAS BIBLIOGRÁFICAS.............. 66 


\section{UTILIZAÇÃO DA VIDEOGRAFIA AÉREA NA DETECÇÃO DE ÁREAS COM DEFICIÊNCIAS NUTRICIONAIS EM PLANTIOS DE EUCALIPTO}

Autor: PAULO POMPERMAYER NETO

Orientador: Prof. Dr. HILTON THADEU ZARATE DO COUTO

\section{RESUMO}

A videografia aérea é uma técnica que vem sendo utilizada nos EUA para avaliação, detecção e prevenção de problemas na agricultura, agricultura de precisão e no manejo de áreas naturais. Um dos motivos para o emprego desta técnica é o seu baixo custo para a obtenção das imagens e a rapidez com que podem ser captadas, processadas e analisadas. Assim sendo, o objetivo deste trabalho foi verificar a utilidade da técnica videográfica no levantamento de problemas nutricionais em plantações de eucalipto, utilizando-a como ferramenta no monitoramento nutricional, tornando-o mais preciso e menos dispendioso que os métodos utilizados atualmente. Para isto, instalouse um experimento com tratamentos de subtração de nutrientes com a finalidade de verificar a potencialidade da videografia aérea como técnica para distinguir os tratamentos com deficiência nutricional nos plantios de 
eucalipto. Foram obtidas imagens nos espectros verde, azul, vermelho e infravermelho próximo, 12 meses após o plantio. Essas imagens foram capturadas com duas câmeras S-VHS: uma capaz de captar a faixa do espectro visível (400 - $700 \mathrm{~nm}$ ) e, outra capaz de captar a faixa do espectro visível mais infravermelho próximo (400 - $1100 \mathrm{~nm})$. Nestas câmeras foram também utilizados filtros de subtração para separar as faixas do espectro a serem trabalhadas. Além disso, com a utilização do software ENVI, foi feita uma análise dos valores de pixels de cada parcela, obtendo-se os valores mínimos, médios, máximo e o desvio padrão da média. Estes valores foram, então, comparados e agrupados conforme análise estatística multivariada, buscando encontrar relações entre os dados das imagens e os tratamentos. Relações significativas entre os dados dendrométricos e os dados de pixel foram encontradas para as imagens obtidas a 1500 metros de altitude pela câmera COHU nos espectros azul e infravermelho próximo e, pela câmera PANASONIC no espectro vermelho. 


\title{
THE USE OF AERIAL VIDEOGRAPHY IN THE DETECTION OF AREAS WITH NUTRICIONAL DEFICIENCY IN EUCALYPTUS PLANTATION
}

\author{
Author: PAULO POMPERMAYER NETO
}

Adviser: Prof. Dr. HILTON THADEU ZARATE DO COUTO

\section{SUMMARY}

The aerial videography is a technique that has been used in the USA to evaluate, detect and prevent agricultural problems, as well as in the handling of natural areas. One of the reasons for the employment of this technique is its low cost for obtaining the images and the speed with that they can be captured, processed and analyzed. The aim of this work was to verify the usefulness of the videography technique in detecting nutritional deficiency in eucalyptus plantations, using it as a tool in the nutritional monitoring, turning it more precise and less costly than the methods used at present. For this, an experiment was settled with treatments of subtraction of nutrients with the purpose of verifying the potentiality of the aerial videography as technique to distinguish the treatments with nutritional deficiency in eucalyptus 
plantation. Images were obtained in the green, blue, red and infrared close spectrum, after 12 months of plantation. Those images were obtained with two cameras S-VHS: one capable of capturing the bands of the visible spectrum (400 - $700 \mathrm{~nm}$ ) and other capable of capturing the bands in the visible and near infrared band (400 - $1100 \mathrm{~nm})$. In these cameras, subtraction filters were also used to separate the bands of the spectrum to work. Besides, with the use of the software ENVI, it was made an analysis of the values of pixels of each portion, being obtained the minimum, medium, maximum values and the mean standard deviation. Then, these values were compared to each other and put together according to the multivariate statistical analysis, looking for relationships between the data of the images and the treatments. Significant relationships between the tree and pixel values data were found for the images obtained in $1500 \mathrm{~m}$ high by the camera COHU, in the spectra blue and close infrared and for the camera PANASONIC, in the red band. 


\section{INTRODUÇÃO}

Os plantios de eucalipto, no Brasil, iniciaram-se na
década de 60, com a madeira sendo utilizada para diversas
finalidades, sendo a principal a produção de biomassa para
energia. Porém, as práticas culturais empregadas não proviam
adubações e não objetivavam a reposição dos nutrientes
exportados através dos produtos retirados. Além disso, devido
aos solos utilizados para os plantios florestais serem, em sua
maior parte, de baixa fertilidade, a exportação dos nutrientes
através dos ciclos de corte promoveram o esgotamento de suas
reservas minerais.

No entanto, com a substituição dos plantios pouco tecnificados por outros, como os de clones das espécies Eucalyptus saligna, E. grandis, E. urophylla e híbridos, de rápido crescimento e características melhoradas para atender as exigências de qualidade industrial, a preocupação com reposição de nutrientes e sustentabilidade da produção tem aumentado.

Atualmente, as empresas utilizam-se de adubações, mas que nem sempre são eficientes para todos os tipos de solo e para todas as espécies ou clones de eucalipto.

Esta heterogeneidade ocasiona, em alguns pontos, regiões onde a exigência nutricional das árvores não é atendida e, em 
outros, regiões onde ocorre o excesso de adubação e a conseqüente lixiviação das sobras, havendo o desperdício de recursos.

Visando detectar essas áreas deficientes, algumas empresas empregam o monitoramento nutricional de seus plantios, estabelecendo parcelas em que crescimento e estado nutricional das plantas são avaliados, principalmente, nos dois primeiros anos, época de maior exigência de nutrientes e ainda em tempo de uma correção por meio de adubação suplementar. Porém, o monitoramento nutricional é um método nem sempre vantajoso.

Algumas desvantagens deste método:

- Emprego de um grande número de análises químicas, necessárias para determinar a nutrição da floresta e a fertilidade do solo;

- Utilização de uma equipe para alocação das parcelas e coleta das amostras;

- Longo período de tempo desde o início do trabalho até a obtenção dos resultados;

- Falta de precisão da área em que se deve utilizar a correção.

Segundo a Sociedade Brasileira de Silvicultura, em 1997, - Brasil possuía 4.652.412 ha de florestas plantadas, sendo 2.949.345 ha de eucalipto. Deste total, apenas 350.000 ha $(11,86 \%)$ eram adubados (Silveira et al., 1995).

No entanto, a maximização dos recursos da adubação, resultaria numa melhor utilização dos nutrientes pelas plantas 
e conseqüente melhoria na conservação dos recursos naturais como a água e o solo.

o objetivo desse trabalho foi estudar a viabilidade do emprego da videografia aérea como um método rápido e de baixo custo para identificar áreas com deficiências nutricionais, otimizando a amostragem em trabalhos de monitoramento nutricional de plantios de eucalipto. 


\section{REVISÃO DE LITERATURA}

\subsection{Início da utilização dos sistemas de videografia aérea}

King (1995), faz um histórico da evolução das câmeras e do desenvolvimento de sistemas utilizando a tecnologia de vídeo como sensor remoto, mostrando as principais características de diversas configurações de sensores remotos não orbitais e ainda listando as vantagens e desvantagens de cada um.

Alguns testes, com a utilização de vídeo como sensor remoto foram realizados nas décadas de 60 e 70 com equipamentos preto e branco de baixa resolução espacial (Robinove \& Skibitzke ${ }^{1}$; Mozer \& Seigel ${ }^{2}$, citados por Everitt et al., 1991b).

Porém, avanços tecnológicos significativos nos equipamentos de vídeo ocorreram somente a partir da década de 80, quando foram realizados por Gausman et al. (1983), os primeiros estudos envolvendo câmeras de vídeo preto e branco, com sensibilidade para captar a faixa do espectro eletromagnético referente ao infravermelho próximo $(0,7$ até 1,1 nm). Mas, os autores utilizaram esse sistema apenas para estudar como diferentes arquiteturas de folhas influenciavam na reflectância do dossel na faixa do infravermelho próximo.

Outros estudos realizados ainda na década de 80 foram o de Richardson et al. (1985), que utilizaram um sistema de

${ }^{1}$ ROBINOVE, C.; SKIBITZKE, H. An airborne multispectral video system. U.S. Geological Survey Professional Paper, v.575-D, p. D143-146. 1967. 
quatro câmeras de vídeo para distinguir ervas daninhas das plantas em cultivo e o de Everitt \& Nixon (1985) onde os autores utilizaram um sistema de quatro câmeras de vídeo para identificar diferentes tipos de uso da terra.

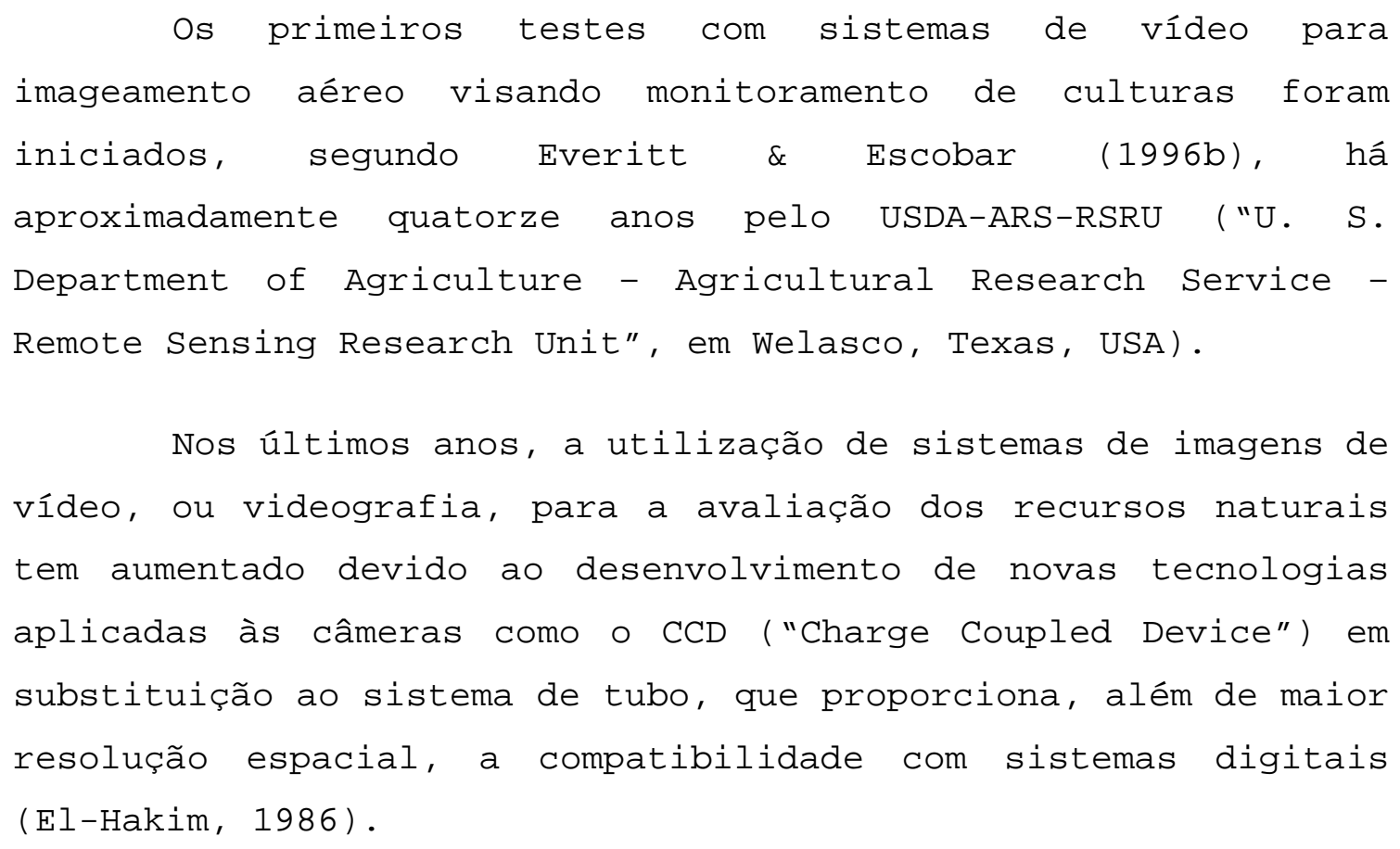
imageamento aéreo visando monitoramento de culturas foram iniciados, segundo Everitt \& Escobar (1996b), há aproximadamente quatorze anos pelo USDA-ARS-RSRU ("U. S. Department of Agriculture - Agricultural Research Service Remote Sensing Research Unit", em Welasco, Texas, USA).

Nos últimos anos, a utilização de sistemas de imagens de vídeo, ou videografia, para a avaliação dos recursos naturais tem aumentado devido ao desenvolvimento de novas tecnologias aplicadas às câmeras como O CCD ("Charge Coupled Device") em substituição ao sistema de tubo, que proporciona, além de maior resolução espacial, a compatibilidade com sistemas digitais (El-Hakim, 1986).

\begin{abstract}
Além disso, os avanços nos sistemas de gravação e processamento das imagens através de computadores também estão viabilizando o uso do vídeo como sensor remoto (Everitt et al., 1991a).
\end{abstract}

\footnotetext{
${ }^{2}$ MOZER, M.; SEIGEL,P. High resolution multispectral TV camera system. In: INTERNATIONAL SYMPOSIUM ON REMOTE SENSING OF ENVIRONMENT, 7., Ann Arbor, 1971. Proceedings. Ann Arbor: ERIM, 1971. p.1475-1480.
} 


\title{
2.2 Vantagens da videografia aérea em relação a outros sensores remotos
}

\begin{abstract}
Nixon et al. (1985), relatam como vantagens dos sistemas de vídeo em relação a outros sensores remotos, a maior fotosensibilidade das câmeras, o que permite a separação das faixas do espectro eletromagnético visível (400 até $700 \mathrm{~nm})$, além da possibilidade de captar a faixa do infravermelho próximo (700 até $1100 \mathrm{~nm})$. Outra vantagem citada pelos autores é a possibilidade de visualização e processamento imediato das imagens.
\end{abstract}

Segundo Everitt et al. (1991b), a grande vantagem da utilização de sistemas de sensoriamento remoto com a utilização de vídeo é a agilidade de coleta, processamento e utilização dos dados, já que este processo pode levar algo em torno de horas, ao invés de semanas ou até meses, requeridos por outros sistemas.

Além disso, os autores destacam a importância do vídeo em aplicações como monitoramento da produção agrícola e avaliação de catástrofes devido à rapidez do processamento das imagens obtidas que facilmente podem ser convertidas para 0 formato digital.

Everitt et al. (1991a) e Everitt et al. (1995) destacam - potencial de rápido processamento digital das imagens como sendo um fator importante na utilização de sistemas de vídeo ao invés de filmes fotográficos. Isto ocorre, principalmente, devido à especificidade do processamento de filmes aéreos e infravermelhos.

Os mesmos autores citam ainda que, devido à alta
sensibilidade à luz, em comparação aos filmes fotográficos, o


vídeo permite trabalhar em faixas espectrais estreitas e no espectro infravermelho próximo, podendo-se também distinguir e quantificar parâmetros do terreno com a utilização de filtros e sistemas computadorizados para processamento das imagens.

Em um trabalho comparando técnicas de sensoriamento remoto com análise em campo para o mapeamento da vegetação, Lowe et al. (1995) avaliaram itens como aquisição de imagens, análise das imagens e relação custo-benefício, chegando à conclusão que a videografia, utilizando filtros infravermelho próximo, vermelho e azul, apresentou-se como o método mais efetivo para o mapeamento da vegetação, tendo o menor custo total de operação (USD 2,735.00).

Segundo esses autores, em termos de custo, a fotografia aérea infravermelha (USD 3,712.00) foi a que mais se aproximou do preço da videografia, seguida da imagem de satélite TM LANDSAT (USD 6,026.00) e da análise de campo.

Os autores citam ainda que apesar da menor resolução da imagem de vídeo em comparação à fotografia, seu resultado tem benefícios consideráveis que a tornam viável.

Também para Everitt \& Escobar (1996b), os sistemas de videografia aérea são menos dispendiosos do que sistemas fotográficos. As fitas de vídeo custam menos do que um filme, aproximadamente USD 15.00, e permitem a gravação de duas horas de imagem, podendo ser regravadas. O custo de um filme infravermelho, incluindo sua revelação está na faixa de USD 200.00 a USD $1,000.00$ por rolo.

Para Yang et al. (1998) as grandes vantagens da videografia em relação às imagens de satélite e outros sensores remotos são a sua alta resolução espacial, disponibilidade 
imediata das informações para análise, o baixo custo e facilidade na operação dos equipamentos.

Couto et al. (2000) citam como principais vantagens do sistema de videografia aérea:

- possibilidade de avaliar a imagem em tempo real;

- simplicidade, baixo custo e facilidade de operação do equipamento;

- possibilidade de identificação e correção de problemas com rota e obtenção das imagens, uma vez que o operador acompanha o vôo por um monitor;

- grande quantidade de imagens adquiridas;

- a integração do sistema de videografia com GPS (Global Positioning System) e com Sistemas de Informações Geográficas.

Portanto, todos os autores acima, são unânimes em destacar o potencial da videografia aérea para a visualização e processamento imediato das imagens, possibilitando a disponibilidade quase instantânea da informação para análise, além disso, seu baixo custo e facilidade na operação dos equipamentos, viabilizam seu emprego em detrimento de outras técnicas. 


\subsection{Limitações do sistema de videografia aérea}

Mausel et al. (1992) citam como problemas do sistema de videografia:

- dificuldade de alinhamento de mais de uma câmera para compor imagens e calcular índices de vegetação;

- necessidade de utilização de um gravador e um monitor para cada câmera do sistema;

- possíveis problemas com codificações de imagens entre aparelhos fabricados em diferentes países.

Para Linden (2000), a utilização de lentes com grande angular prejudicam a resolução da imagem, assim como a impressão que ainda é uma limitação do sistema de imagens digitais.

King (1995) e Um \& Wright (1999) citam a transição das imagens do sistema de vídeo analógico para o digital, ou seja, a captura das imagens, como um fator limitante por proporcionar perda de qualidade das imagens.

\subsection{Emprego da videografia aérea em culturas}

A videografia pode monitorar diversos parâmetros no terreno estudado, como: verificar a presença de ervas daninhas, fazer a diferenciação entre a grama adubada e a não adubada, localizar áreas queimadas e infestações de formigas (Everitt \& Nixon, 1985). 
As imagens de vídeo podem ainda gerar dados digitais e índices de vegetação para estimar a altura do dossel de plantas, área foliar e a produtividade desse plantio(Richardson et al., 1990; Wiegand et al., 1992; Wiegand et al., 1994; Yang \& Anderson, 1996; Yang \& Anderson 1997).

Sistemas de vídeo podem ser utilizados também, como apoio em análises térmicas de incêndios florestais, empregandose câmeras aptas a captar a faixa referente ao infravermelho termal do espectro eletromagnético $(10,4-12,5 \mu \mathrm{m})$ (Everitt et al., 1989b).

Além disso, os sistemas de vídeo podem ainda gerar, a partir de imagens obtidas em câmeras preto e branco, contrastes de falsa cor como as do sistema utilizado por Nixon et al. (1987), para detectar apodrecimento de raízes em algodão, cujos sintomas se refletem no baixo crescimento da planta, clorose e morte da parte aérea.

Os autores também utilizaram o sistema para mapear áreas com encharcamento e monitorar a drenagem sub-superficial do solo.

As limitações de trabalho com mais de um espectro, associadas à utilização de um sistema de câmera simples, foram resolvidas com $\circ$ desenvolvimento de sistemas de câmeras múltiplas, como fizeram Nixon et al. (1985), utilizando quatro câmeras branco e preto, cada uma com um filtro diferente, e um gravador Betamax.

Richardson et al. (1985) também utilizaram um sistema de quatro câmeras para diferenciar plantas daninhas das culturas de algodão e sorgo e estimar a produtividade das culturas 
usando uma classificação supervisionada para demarcar diferentes aéreas.

Everitt et al. (1986a), combinando filtros de luz, atingiram a faixa de 1450 - $2000 \mathrm{~nm}$, região sensível à luz de absorção da água, ou infravermelho médio. Os autores utilizaram essa faixa de onda para distinguir a grama com estresse hídrico.

Everitt et al. (1987) utilizaram o mesmo procedimento para diferenciar espécies suculentas de não-suculentas.

Everitt et al. (1988a) utilizaram um sistema de quatro câmeras de vídeo para montar índices de vegetação e avaliar seu potencial para monitorar a produção de biomassa com parcelas de grama adubadas com nitrogênio, nas doses de 0, 56, 112, 168 e $224 \mathrm{~kg} \cdot \mathrm{ha}^{-1}$.

Os autores utilizaram onze filtros de luz para adquirir as imagens, seis semanas após a aplicação da adubação, obtendo coeficientes de determinação significativos para a relação entre reflectância e doses de nitrogênio. Essas imagens foram obtidas através de filtros laranja-vermelho, vermelho, vermelho escuro e infravermelho.

Além de obterem índices de correlação $\left(r^{2}\right)$ significativos, os autores citam que foi possível realizar uma avaliação qualitativa das imagens obtidas com esses quatro filtros.

Everitt et al. (1988b) detectaram problemas com a salinidade de solos em áreas agrícolas utilizando imagens obtidas no espectro infravermelho. 
Hart et al. (1988) também utilizaram um sistema de imagem infravermelha para detectar a clorose (amarelecimento ocasionado por problemas nutricionais ou de raízes) em árvores do gênero Citrus.

Everitt et al. (1991c) utilizaram o sistema multiespectral de vídeo de alta resolução para mapear as populações de "black mangrove" (Avicennia germinans L.), planta invasora, com distribuição em áreas tropicais e subtropicais, na região do Golfo do Texas (EUA) .

Everitt et al. (1991d), demonstraram que áreas infestadas com "prickilypear" (Opuntia lindheimeri Engelm.), uma espécie de cacto, podem ser diferenciadas de áreas não infestadas utilizando-se imagens de vídeo com filtro infravermelho médio. O infravermelho médio também tem 0 potencial de diferenciar condições da superfície do solo (Everitt et al., 1989a).

Yang et al. (1998) utilizaram um sistema de videografia aérea para obter índices de produtividade em sorgo, obtendo correlações significativas entre os valores de pixel e os teores de $\mathrm{P}, \mathrm{K}, \mathrm{Ca}$ e Mn nas folhas, assim como uma estimativa muito próxima da produtividade de grãos.

Schlemmer et al. (1998) utilizaram imagens de vídeo multiespectral com os filtros azul (489 nm), verde (559 nm), vermelho (657 nm) e infravermelho próximo (841 nm) para estimar a biomassa e a produção de milho (Zea mays L.) através dos índices extraídos dos dados digitais das imagens de vídeo. 0 coeficiente de correlação para as curvas ajustadas para biomassa e produção de grãos foi de 0,8 e 0,87, respectivamente. 
O emprego da videografia aérea no monitoramento de culturas apresentou dificuldades no início dos trabalhos devido à utilização de câmeras simples porém, com o passar do tempo, através de vários experimentos e dos ajustes que foram sendo feitos, principalmente no que se refere ao uso de câmeras múltiplas e de filtros de luz de faixas variadas, incluindo a faixa do infravermelho, as limitações de trabalho foram sendo superadas.

\subsection{Comparação entre a videografia aérea e outros sensores remotos}

Sobrevoando um campo de sorgo próximo a Welasco, Texas (EUA) a uma altitude de 2300 m, com um sistema multiespectral de vídeo de alta resolução, preto e branco, com filtro de luz azul, Everitt et al.(1991a) obtiveram imagens onde as plantas cloróticas tinham coloração cinza claro, enquanto nas plantas sadias a coloração era cinza escuro.

Em seguida, por meio de uma análise computadorizada da imagem, distinguiu-se as áreas de plantas cloróticas das demais, estimando-as em 41\% da área total.

Essa análise foi comparada à de uma imagem fotográfica, que obtinha como resultado 43\% da área total, demostrando dessa forma, a viabilidade do sistema de vídeo em substituição às fotografias aéreas no monitoramento de culturas (Everitt et al., 1988b).

Everitt et al.(1991b), a fim de comparar a videografia aérea com a fotografia aérea, utilizaram sistemas 
multiespectrais de vídeo de alta resolução (400 - 565 linhas) para diversas aplicações em agricultura:

- avaliação dos efeitos da erosão eólica em algodão (Gopssypium hirsutum L.);

- identificação dos efeitos da infestação da broca da cana-deaçúcar (Eoreuma loftini Dyar);

- detecção de áreas com clorose, ocasionada por deficiência de ferro em sorgo (Sorghum bicolor L.);

- deteç̧ão de podridão de raízes em alfafa (Medicago sativa L. ) ;

- mapeamento de áreas infestadas por formigas cortadeiras.

Comparando as imagens tomadas a uma altitude de $1100 \mathrm{~m}$, os autores concluíram que a videografia aérea, estimou em 1\% a área infestada por formigas, enquanto que a fotografia aérea, estimou em $1,3 \%$.

Everitt et al. (1998), com o objetivo de simular as bandas 5,3 e 4 do satélite TM LANDSAT, que captam as faixas do espectro 1550-1750 nm, 760-900 nm e 630-690 nm respectivamente, utilizaram um sistema de vídeo constituído por três câmeras:

a) duas câmeras CCD COHU 4800 séries aptas a captar as faixas do espectro visível e o infravermelho próximo (400-1100 nm) sendo uma delas equipada com filtro para captar o vermelho visível (625-635 nm) e a outra equipada com filtro infravermelho próximo (845-857 nm); 
b) uma câmera Hamamatsu C2741-03 capaz de captar as faixas do espectro visível, infravermelho próximo e infravermelho médio (400-2200 nm), equipada com filtro infravermelho médio (1631-1676 $\mathrm{nm})$.

Com esse sistema de vídeo constituído de três câmeras, os autores puderam distinguir diversas características ecológicas da área analisada, com uma maior resolução espectral que a do sensor orbital.

Portanto, de acordo com as experiências relatadas pelos diversos autores, os resultados obtidos com 0 uso da videografia aérea em relação a outros sensores remotos são quase idênticos, o que reforça a viabilidade de sua utilização.

\subsection{Utilização de filtros em câmeras de vídeo}

Nixon et al. (1985) e Everitt et al. (1988a) assim como Mausel et al. (1993), utilizaram filtros em câmeras de vídeo com o objetivo de destacar em faixas especificas do espectro eletromagnético, determinadas características do terreno analisado.

Os filtros de luz e os respectivos comprimentos de onda espectral utilizados em câmeras de vídeo, segundo Everitt et al. (1988a), Everitt et al. (1989a) e Everitt et al. (1990) estão apresentados na Tabela 1 . 
Tabela 1. Filtros de luz utilizados em câmeras de vídeo e a faixa de comprimento de onda em que atuam.

\begin{tabular}{lr}
\hline \multicolumn{1}{c}{ FILTRO } & SENSIBILIDADE $(\mathrm{nm})$ \\
\hline AZUL & $467-473$ \\
VERDE & $516-524$ \\
AMARELO-VERDE (AZUL) & $543-552$ \\
AMARELO & $573-583$ \\
LARANJA & $586-595$ \\
LARANJA-VERMELHO & $614-625$ \\
LARANJA ESCURO-VERMELHO & $633-645$ \\
VERMELHO & $644-656$ \\
VERMELHO ESCURO & $656-668$ \\
VERMELHO ESCURO INTENSO & $712-725$ \\
INFRAVERMELHO & $815-827$ \\
INERAVERMELHO MÉDIO & $1450-2000$ \\
\hline
\end{tabular}

Filtros para captar imagens de vídeo nas faixas referentes ao verde, vermelho e infravermelho próximo foram utilizados por Yang et al. (1998), em um sistema de câmeras alinhadas, com o objetivo de calcular índices de vegetação para estimativa de produtividade de sorgo.

Schlemmer et al. (1998), utilizando um sistema de câmeras com filtros, conseguiram boas correlações entre índices obtidos, através das imagens e acúmulo de biomassa e produtividade. 


\title{
2.7 Integração com sistema de informações geográficas
}

\begin{abstract}
Imagens de vídeo podem ser integradas com geradores de caracteres que inserem as posições geográficas, provenientes de um aparelho de GPS (Global Positioning System) nas imagens. Além disso, as imagens também podem ser georeferenciadas e utilizadas sobre um mapa, montando uma ótima caracterização do terreno (Linden, 2000).
\end{abstract}

Everitt et al. (1994) conduziram estudos utilizando videografia aérea, GPS e SIG para detectar e mapear a infestação de "Citrus Blackfly", ou "mosca preta do Citrus" (Aleurocanthus woglumi Asby) em pomares de Citrus, no vale do Baixo Rio Grande, Texas, (EUA).

Everitt et al. (1996a) utilizaram imagens coloridas de vídeo, sem utilização de qualquer filtro, integradas com GPS para detectar infestações de Tamarisk chinensis Lour., espécie de planta introduzida como paisagística, e utilizada no controle de erosão em áreas ripárias ao longo do Rio Grande, Texas (EUA). Essas imagens foram georeferenciadas por meio de um sistema de GPS integrado ao sistema de vídeo, o que possibilitou um posterior mapeamento das áreas com a utilização de SIG.

Análises tridimensionais para avaliação do terreno também podem ser obtidas em imagens de vídeo digitalizadas e georeferenciadas por meio de softwares, com isso barateando 0 custo desse tipo de análise, que geralmente é realizada com o emprego de fotografias aéreas (King, 1995).

Conforme exposto acima, o sistema de imagens de vídeo pode ser integrado com obtenção de ótimos resultados aos 
sistemas GPS (Global Positioning System) e SIG (Sistema de Informação Geográfica).

\subsection{Emprego de sensores remotos em monitoramento nutricional de eucalipto}

O sensoriamento remoto vem sendo testado para o monitoramento de plantios de eucalipto. É o que os autores Ponzoni \& Gonçalves (1997) relatam ao terem utilizado imagens TM LANDSAT para tentar detectar deficiências de potássio em plantios jovens.

Ponzoni \& Gonçalves (1999) mostraram que deficiências de potássio em mudas de eucalipto podem ser radiometricamente detectadas, porém concluíram que deficiências nutricionais não podem ser diferenciadas em faixas estreitas de resolução espectral.

Segundo Shimabukuro (1996), que avaliou classificadores espectrais de imagens TM LANDSAT em áreas rurais na região de Brotas e Torrinha, as principais aplicações das bandas espectrais TM são:

- Azul - 450-520nm (banda 1): como o pigmento clorofila presente nas folhas verdes geralmente absorve de $70 \%$ a $90 \%$ da luz na região azul do espectro eletromagnético, com um pico de absorção situado ao redor de $450 \mathrm{~nm}$, os dados dessa faixa são úteis para discriminação de tipos florestais, diferenciações entre o solo e a vegetação e a identificação de características das culturas como perturbações fisiológicas ou deciduidade; 
- Verde - 520-600 nm (banda 2): os pigmentos clorofila, carotenóides e antocianina presentes nas folhas absorvem muito pouco a região verde do espectro, realçando o vigor fenológico e características das culturas;

- Vermelho - 630-690 nm (banda 3): a clorofila absorve de 70\% a 90\% da luz da região vermelha do espectro (em torno de 650 $\mathrm{nm})$, portanto, o processo de senescência foliar ou qualquer distúrbio fisiológico resulta em um aumento da reflectância do visível, principalmente na região do vermelho, devido à degradação da clorofila ou perda de eficiência fotossintética, permitindo a diferenciação de espécies vegetais e identificação de características das culturas;

- Infravermelho próximo - 760-900 nm (banda 4): a reflectância eleva-se muito na faixa de 700-1350 nm, devido à falta de absorção destes comprimentos de onda tanto pelos pigmentos como pela água líquida, sendo os fatores responsáveis por esta variação a estrutura interna das folhas, associada à variação do tamanho e forma das células e dos espaços intercelulares. A reflectância do infravermelho médio também pode ser sensível a alterações metabólicas no mesófilo foliar, apresentando valores maiores em folhas saudáveis do que nas senescentes ou acometidas por fatores fitopatológicos. Essa faixa é adequada para classificação da vegetação, avaliação do vigor fenológico, da biomassa, da umidade edáfica e para a delimitação de corpos d'água.

As características dos sintomas de deficiência dos nutrientes nitrogênio, fósforo, potássio e boro, conforme Epstein (1975) e Malavolta et al. (1997) são: 
- Nitrogênio: inicialmente as folhas mais velhas apresentam a coloração verde-clara, ficando amareladas com pequenos pontos avermelhados ao longo do limbo. Isto ocorre devido ao baixo teor de clorofila e de outros pigmentos. Em seguida, os pontos cobrem toda a lâmina, generalizando o avermelhamento e queda das folhas.

- Fósforo: as folhas mais velhas ficam com coloração verdeescuro, mostrando um arroxeamento próximo às nervuras e pontuações escuras ao longo do limbo, devido ao aumento de pigmentos vermelhos ou roxos e do conteúdo de carboidratos, chegando, em estágio avançado, à necrose.

- Potássio: ocorre um avermelhamento progressivo dos bordos para o centro das folhas mais velhas devido ao aumento no teor de putrescina, ocorrendo em estágio agudo o secamento das folhas. Este nutriente também está relacionado com a fotossíntese, sendo que na sua deficiência verifica-se a redução da taxa fotossintética e paralisação da atividade cambial.

- Boro: as folhas novas apresentam intensa clorose marginal seguida de secamento das margens. As nervuras tornam-se extremamente salientes com posterior necrose. As folhas recém brotadas apresentam-se encarquilhadas e espessas. Ocorre perda da dominância devido à morte da gema apical, podendo ocorrer a seca de ponteiro e morte descendente de 
ramos, conjuntamente com superbrotamento das gemas laterais ao longo do caule. As plantas mostram-se mais susceptíveis à infestação de ácaros, pulgões e fungos (Silveira, 1996). O diâmetro do caule e o crescimento em altura ficam paralisados. 


\section{MATERIAL E MÉTODOS}

\subsection{Local}

O experimento foi conduzido na fazenda Santa Fé, de propriedade da Chamflora Agroflorestal Ltda., Município de Brotas, Estado de São Paulo. A região onde foi montado o experimento foi escolhida por possuir solo tipo areia quartzosa profunda, álica, com horizonte A moderado (AQ), de baixa fertilidade e baixa retenção de água.

A região é sujeita a déficit hídrico de abril a setembro, com uma pequena reposição em junho, conforme mostra o balanço hídrico feito com dados coletados pela estação meteorológica do IAC em Jaú, no período de 1956 - 1982 (Figura 1) .

O relevo da região do ensaio é predominantemente suave ondulado. A temperatura média anual varia entre $21,8{ }^{\circ} \mathrm{C}$ e 23,0 ${ }^{\circ} \mathrm{C}$, tendo a temperatura média mais alta em fevereiro $\left(25,1{ }^{\circ} \mathrm{C}\right) \mathrm{e}$ a mais baixa em junho $\left(18,7{ }^{\circ} \mathrm{C}\right)$. O clima da região é classificado como subtropical úmido com um inverno seco e um verão chuvoso, Cwa, segundo o sistema de Köppen. 


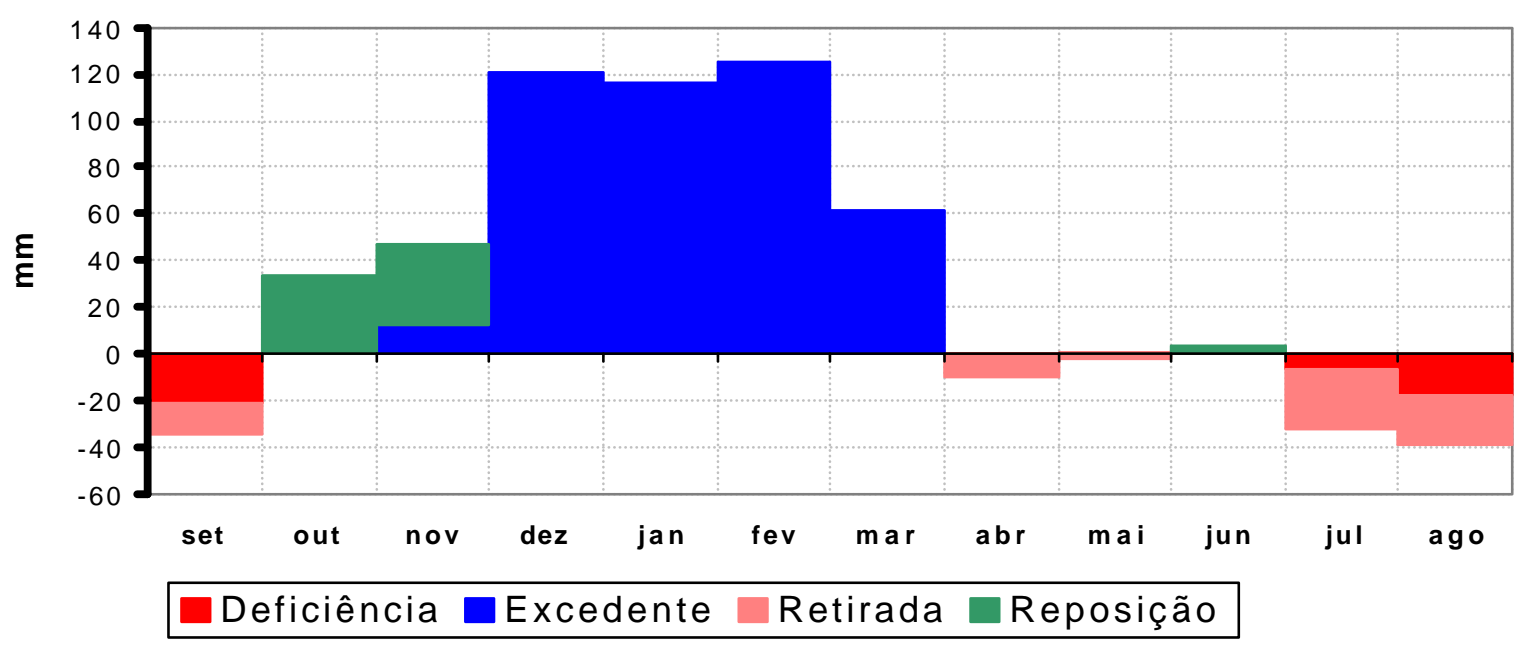

Figura 1 - Balanço hídrico para a região de Jaú, SP (média dos dados de 1956-1982). Dados da estação experimental do IAC, $22^{\circ} 17^{\prime} \mathrm{S}, 48^{\circ} 34^{\prime} \mathrm{W}$, altitude de $580 \mathrm{~m}$ (Adaptado de Aidar, 1992).

\subsection{Delineamento estatístico e instalação do experimento}

O experimento de subtração de nutrientes foi instalado no delineamento inteiramente casualizado com três repetições. As parcelas utilizadas foram de forma quadrada, com 100 plantas e área de $900 \mathrm{~m}^{2}$ cada uma. Para a mensuração dos dados dendrométricos, coleta de solo e de material vegetal para análises, foram utilizadas apenas as 36 árvores centrais de cada parcela.

Malavolta et al. (1997) relatam que nas condições do Brasil, as manifestações mais comuns de deficiência obedecem à seguinte ordem decrescente: macronutrientes - N, P, K, Mg, S e $\mathrm{Ca}$; micronutrientes $-\mathrm{B}=\mathrm{Zn}, \mathrm{Cu}, \mathrm{Fe}, \mathrm{Mn}$ e Mo.

Assim sendo, com o objetivo de induzir as deficiências nutricionais de maior ocorrência em plantações de eucalipto, 
escolheu-se para os tratamentos de subtração de nutrientes (Tabela 2), os macronutrientes nitrogênio (N), fósforo (P), potássio (K) e o micronutiente boro (B) .

Tabela 2. Tratamentos aplicados no experimento de subtração de nutrientes.

\begin{tabular}{cccccc}
\hline Tratamentos & $\mathrm{N}$ & $\mathrm{P}$ & $\mathrm{K}$ & $\mathrm{B}$ & $\mathrm{DENOMINAÇÃO}$ \\
\hline $\mathrm{T}-$ 1 $^{*}$ & + & + & + & + & $\mathrm{NPKB}$ \\
$\mathrm{T}-2$ & + & + & + & - & $\mathrm{NPK}$ \\
$\mathrm{T}-3$ & + & + & - & + & $\mathrm{NPB}$ \\
$\mathrm{T}-4$ & + & - & + & + & $\mathrm{NKB}$ \\
$\mathrm{T}-5$ & - & + & + & + & $\mathrm{PKB}$ \\
$\mathrm{T}-6$ & - & - & + & + & $\mathrm{KB}$ \\
$\mathrm{T}-7$ & - & - & - & + & $\mathrm{B}$ \\
$\mathrm{T}-8$ & - & - & - & - & $\mathrm{NADA}$ \\
$\mathrm{T}-9$ & - & + & - & + & $\mathrm{PB}$ \\
$\mathrm{T}-10$ & + & - & - & + & $\mathrm{NB}$ \\
\hline
\end{tabular}

* adubação recomendada para o local;

+ = nutriente presente;

- = nutriente ausente.

Esses nutrientes foram escolhidos por causa da maior ocorrência de problemas em plantações de eucalipto, devido sua deficiência (Silveira et al., 1995).

Utilizou-se na implantação do experimento um único clone híbrido de Eucalyptus grandis X Eucalyptus urophylla, visando maior homogeneidade do material genético, plantado no espaçamento $3 \mathrm{~m} \times 3 \mathrm{~m}$.

A adubação operacional recomendada para o local possui a seguinte formulação: $1000 \mathrm{~kg}$ de calcário dolomítico.ha-1; $175 \mathrm{~kg}$ 
de N.ha' ${ }^{-1} 500 \mathrm{~kg}$ de $\mathrm{P}_{2} \mathrm{O}_{5} \cdot \mathrm{ha}^{-1}$ e $170 \mathrm{~kg}$ de $\mathrm{K}_{\mathbf{2}} \mathrm{O} \cdot \mathrm{ha}^{-1}$, aplicados na ocasião do plantio e aos três meses de idade.

As adubações dos tratamentos de omissão de nutrientes foram formuladas conforme os teores da adubação operacional, substituindo os componentes do adubo para cada tratamento, visando obter a subtração dos nutrientes estudados em cada um.

\subsection{Montagem do sistema de videografia}

\subsubsection{Câmeras utilizadas e sua instalação no avião}

Para a montagem do sistema utilizado no trabalho, foram utilizadas câmeras S-VHS, devido à maior resolução e qualidade de cor quando comparadas com câmeras VHS (LUSCH, 1988).

As câmeras utilizadas para a obtenção das imagens foram as seguintes:

- Câmera COHU, modelo 2222 (Figura 2A), colorida, com qualidade de imagem de 450 linhas ou 752 x 582 pixels e 30 quadros por segundo, apta à captar a faixa do espectro visível e infravermelho próximo (400-1100 nm).

- Câmera PANASONIC (Figura 2B), modelo AG-456UP, formato SVHS, colorida e qualidade de imagem de 450 linhas e 30 quadros por segundo, apta à captar a faixa do espectro visível (400-700 $\mathrm{nm})$. 

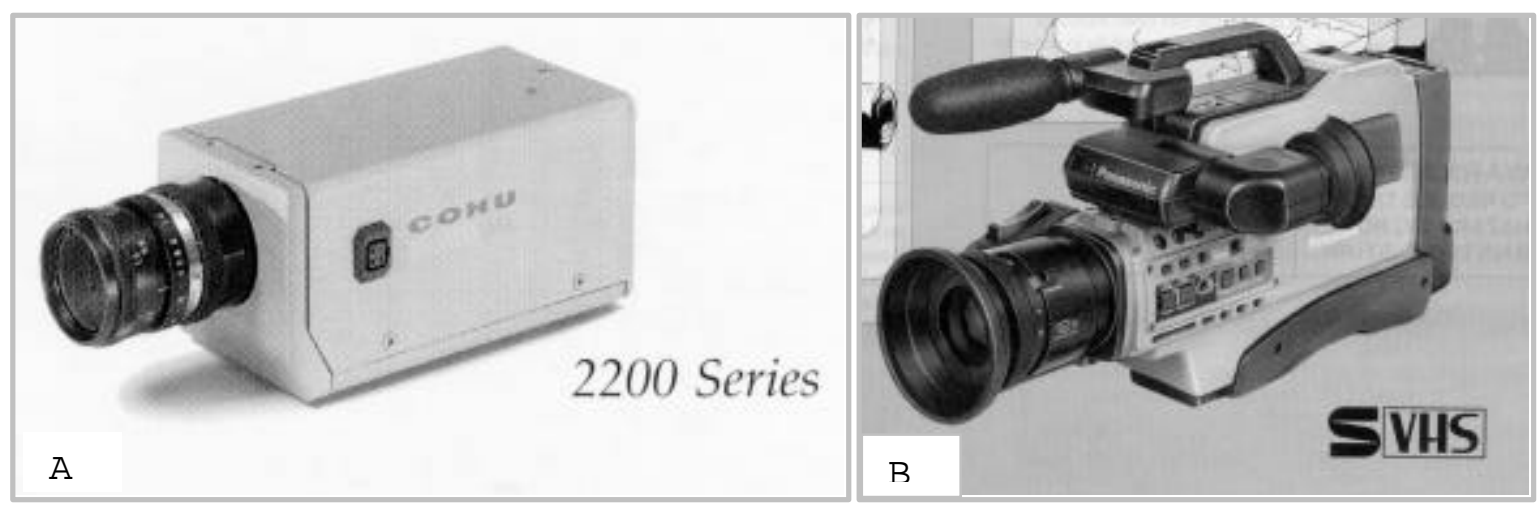

$\begin{aligned} \text { Figura } 2- & \text { Câmeras } \mathrm{COHU}^{3} \text { (A) e PANASONIC }{ }^{4} \text { (B) utilizadas na } \\ & \text { aquisição das imagens. }\end{aligned}$

Para o funcionamento da câmera COHU, uma vez que ela não dispõe de mecanismo de gravação e alimentação, foi montado um sistema com um gravador de vídeo S-VHS e um sistema para fornecimento de energia, composto por um inversor de 12 Volts DC para 110 Volts AC e uma bateria de 12 Volts.

Foi construído um suporte para fixação de ambas as câmeras em uma abertura no piso de um avião CESSNA, modelo 180 (Figuras 3 e 4). O avião foi escolhido porque ele se alinha horizontalmente em relação ao solo quando em vôo, o que é necessário para se obter imagens verticais do alvo.

As câmeras foram ligadas a monitores de vídeo, que exibem o alvo filmado no instante da passagem, possibilitando com isto detectar e corrigir problemas com a rota do avião ou de regulagem dos equipamentos.

\footnotetext{
${ }^{3}$ COHU ELECTRONICS DIVISION. Câmera CohU. San Diego, 1997. 1p. ${ }^{4}$ MATSUSHITA ELECTRIC. Câmera Panasonic S-VHS/VHs - Manual de instruções. Okayama, 1997. 31p.
} 


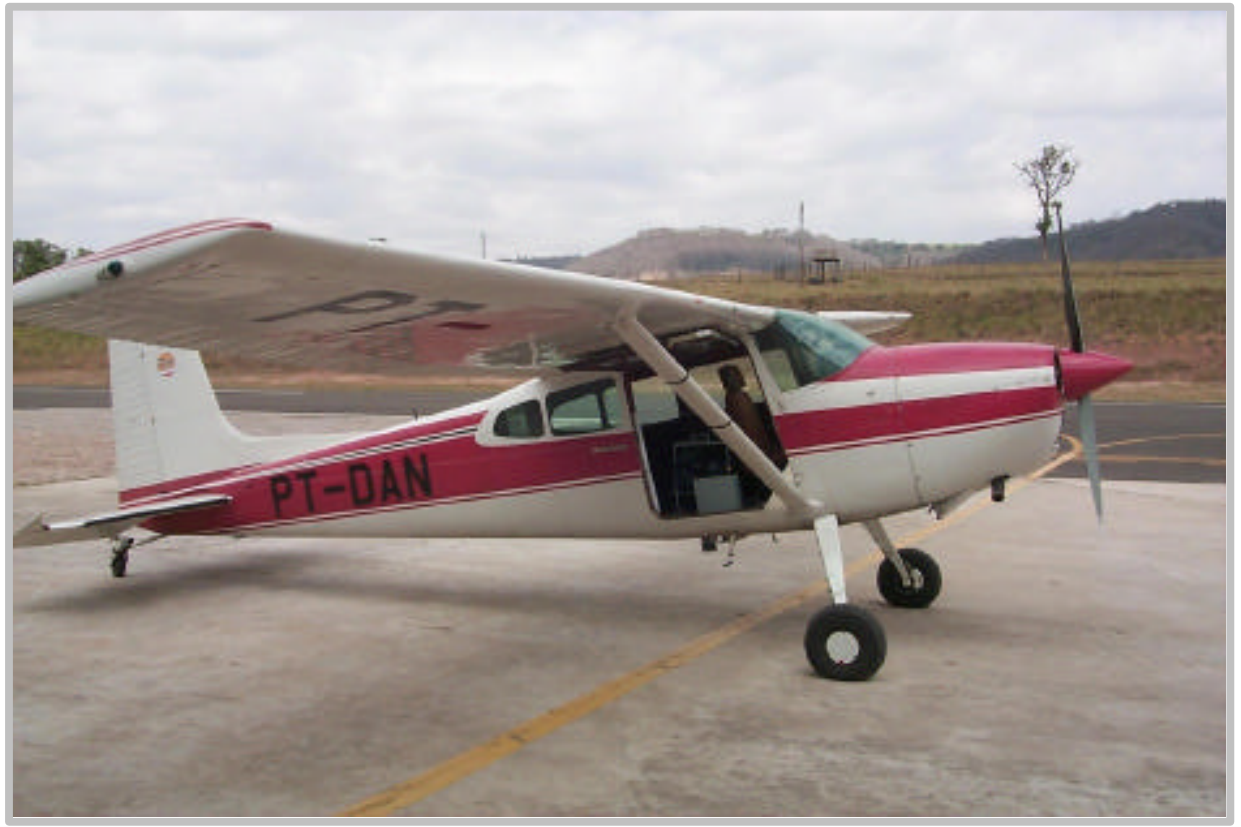

Figura 3 - Avião CESSNA, modelo 180, utilizado na realização do trabalho.

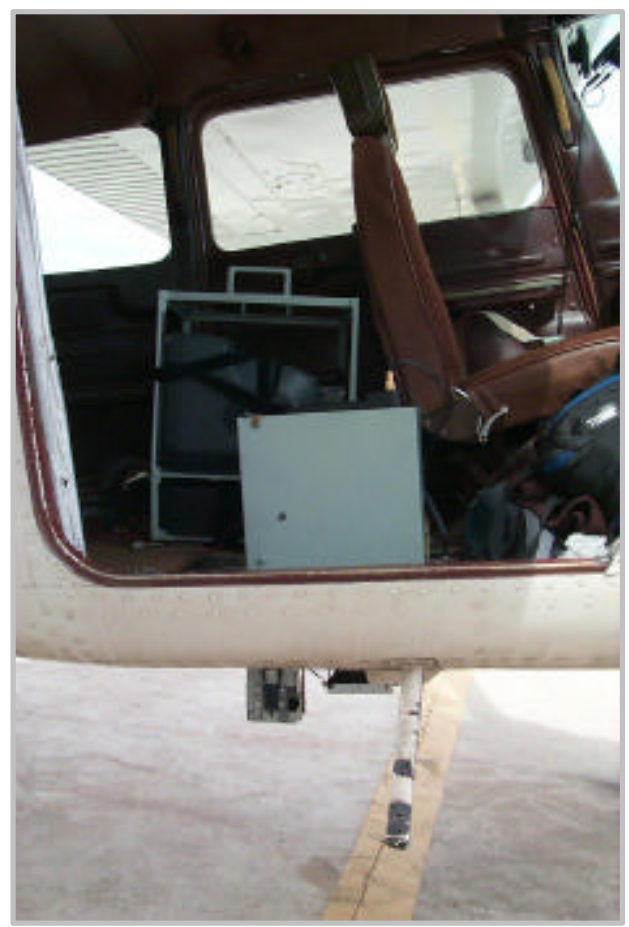

Figura 4 - Fixação das câmeras no piso do avião. 


\subsubsection{Filtros}

A faixa visível do espectro eletromagnético foi dividida nas faixas de onda referentes às cores azul, verde e vermelha. Isto foi realizado para verificar a sensibilidade das câmeras de vídeo em detectar diferenças entre os tratamentos nestas faixas (Figura 5).

$\mathrm{Na}$ câmera COHU, que capta o infravermelho próximo, foi ainda subtraída toda a faixa do espectro visível.

$$
\text { Para a subtração dessas faixas do espectro }
$$
eletromagnético foram utilizados filtros restritivos à um determinado comprimento de onda, conforme características de

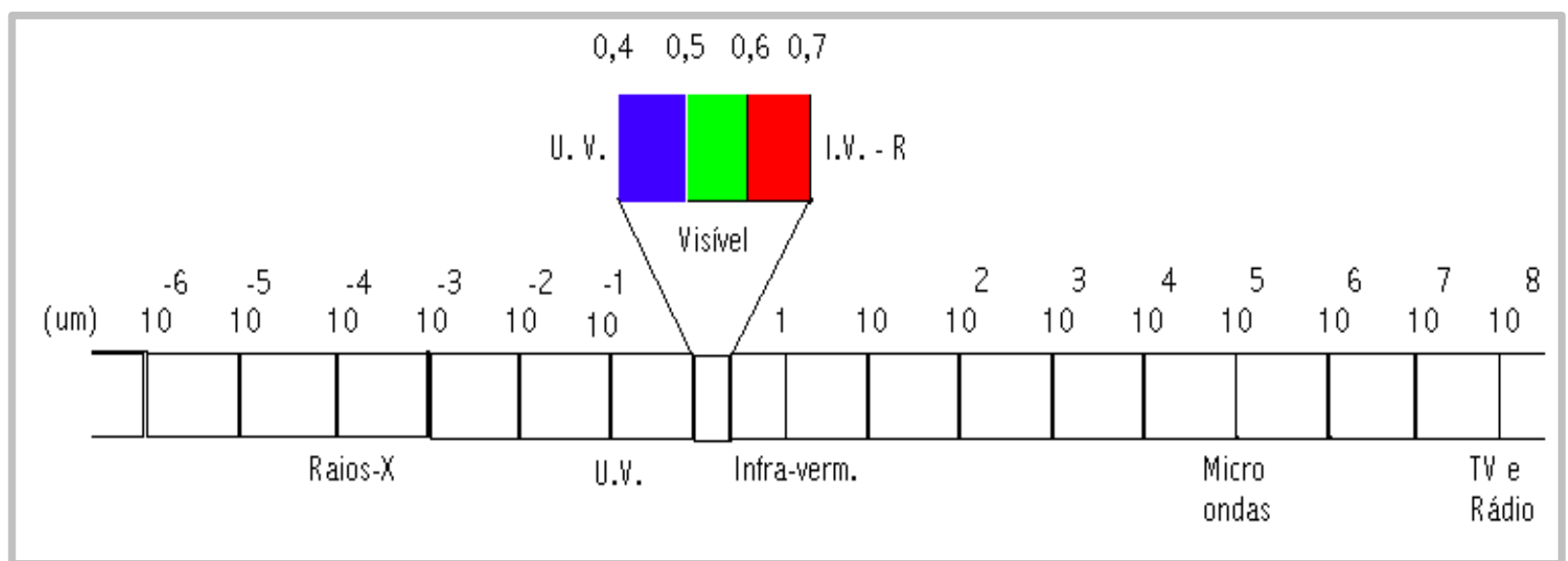

cada espectro ou banda (Shimabukuro, 1996).

Figura 5 - Espectro eletromagnético, com destaque para a região do visível.

Devido à dificuldade de obtenção de filtros de subtração de faixas do espectro eletromagnético no mercado nacional, foram montados filtros utilizando vidro 100\% transparente e 
filmes plásticos, conhecidos como "gelatinas", muito utilizados por profissionais de iluminação.

\begin{abstract}
As "gelatinas" utilizadas no trabalho foram da marca ROSCO, linha supergel, escolhidas pela boa qualidade e por possuírem os dados de transparência e transmitância de todos os filmes.
\end{abstract}

Para a montagem dos filtros foram utilizadas as seguintes gelatinas:

- amarelo médio, com transparência de 92\% e transmitância de $400 \mathrm{~nm}$ - $500 \mathrm{~nm}$ abaixo de 30\%, utilizada para subtrair a faixa azul do espectro eletromagnético;

- azul primário (ciano), com transparência de 9\% e transmitância de $500 \mathrm{~nm}$ - $600 \mathrm{~nm}$ abaixo de 30\%, utilizada para subtrair a faixa do espectro eletromagnético correspondente ao verde;

- Magenta, com transparência de 6\% e transmitância de $600 \mathrm{~nm}$ $700 \mathrm{~nm}$ abaixo de 30\%, utilizada para subtrair a faixa do espectro eletromagnético correspondente ao vermelho.

As gelatinas foram sobrepostas, como pode ser visto na Tabela 3, de forma a transparecer apenas a faixa do espectro desejada, seguindo o diagrama de composição de cores montadas com as próprias gelatinas (Figura 6). 
Tabela 3. Composição de filmes para montar os filtros de subtração .

\begin{tabular}{cc}
\hline Faixa desejada & Gelatinas utilizadas \\
\hline azul & magenta + ciano \\
verde & ciano + amarelo \\
vermelho & magenta + amarelo \\
infravermelho & magenta + ciano + amarelo \\
\hline
\end{tabular}

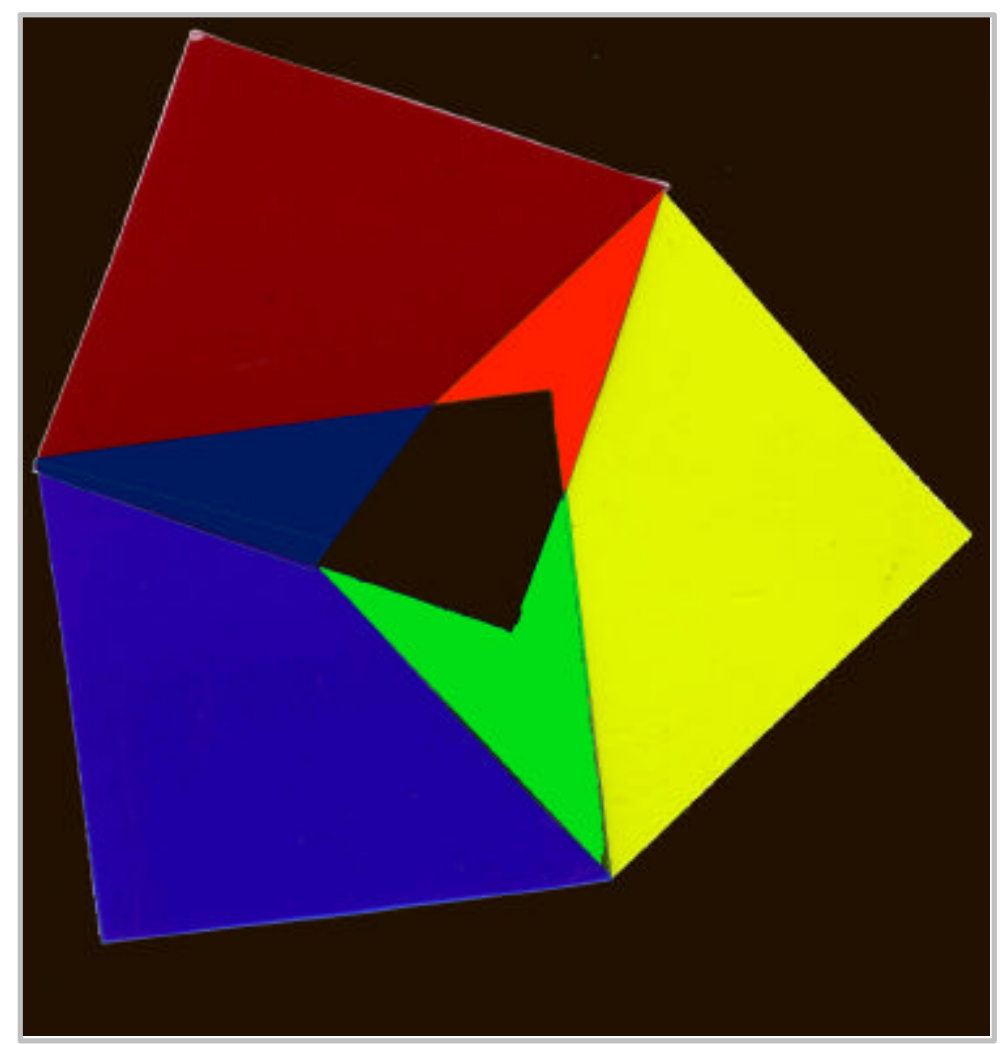

Figura 6 - Diagrama de composição de cores montado com as "gelatinas". 
Os filtros foram fixados nas câmeras por meio de suportes que permitissem boa fixação e rapidez nas trocas, que seriam efetuadas a cada sobrevôo (Figura 7).

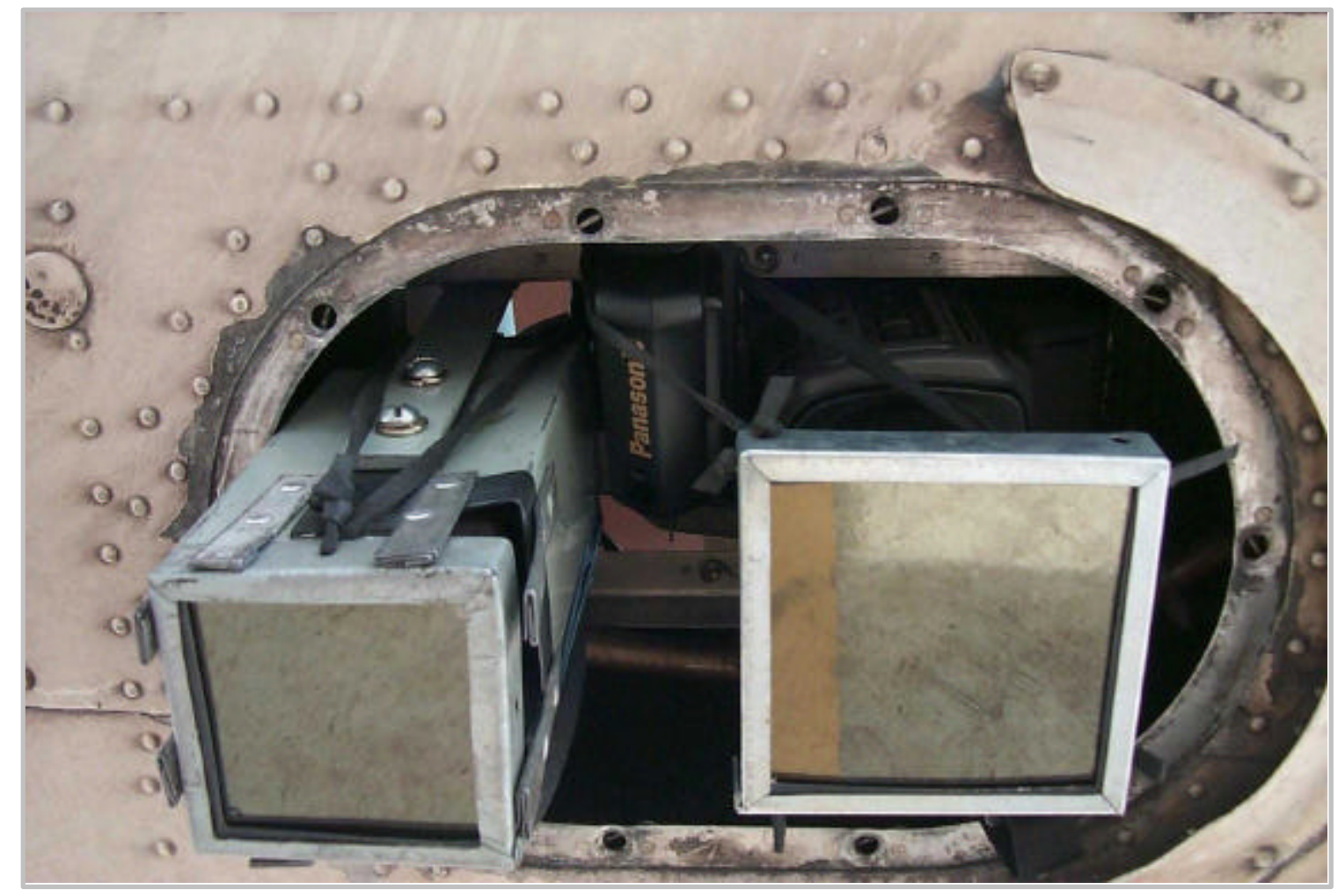

Figura 7 - Detalhe da fixação dos filtros de subtração nas câmeras instaladas no avião.

\subsection{Sobrevôo}

O sobrevôo foi realizado em um dia sem nuvens e com boa visibilidade. Anteriormente foi feito um planejamento para que - sobrevôo ocorresse entre as 10:00 h e 14:00 h, em duas altitudes: $1500 \mathrm{~m}$ e $3000 \mathrm{~m}$ do solo.

Utilizou-se como base a pista da fazenda Santa Inês, município de Brotas, SP, por ser asfaltada e permitir o fácil acesso por terra ao experimento. 
A pista está a 40 minutos de vôo do aeroclube de Piracicaba e a 5 minutos do local do experimento. Nela foram efetuadas a calibração do altímetro, a montagem dos equipamentos e a troca dos filtros em cada sobrevôo.

Para ambas as câmeras, foram realizados sobrevôos para obtenção de imagens com a faixa do espectro visível fracionado nos comprimentos de onda referentes ao azul, verde e vermelho.

Um outro sobrevôo foi feito para se obter imagens com a câmera PANASONIC da faixa visível do espectro eletromagnético sem fracionamento e, com a câmera COHU, apenas da faixa do espectro eletromagnético correspondente ao infravermelho próximo. Os sobrevôos e as imagens obtidas em cada um estão apresentados na Tabela 4 .

Tabela 4. Imagens obtidas em cada sobrevôo.

\begin{tabular}{ccc}
\hline Sobrevôo & Câmera CoHU & Câmera Panasonic \\
\hline 1 & azul + infravermelho próximo & azul \\
2 & verde + infravermelho próximo & verde \\
3 & vermelho + infravermelho próximo & vermelho \\
4 & infravermelho próximo & visível \\
\hline
\end{tabular}

\subsection{Captura das imagens}

As imagens obtidas da área experimental, em fitas S-VHS, foram digitalizadas para o computador através de uma placa de captura de vídeo Pinacle Miro DC 30 Plus (Figura 8). 


\section{DC30 plus Circuit Board}
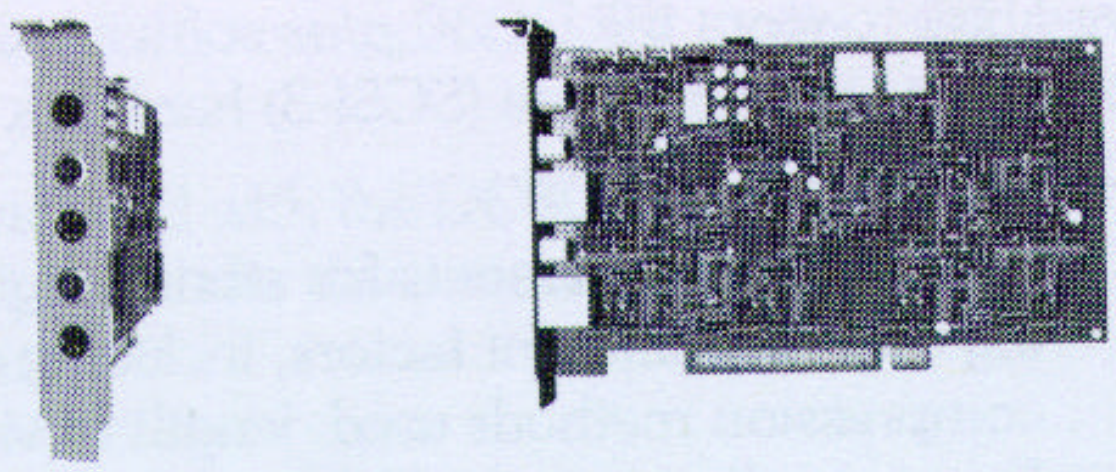

Figura 8 - Placa de captura de vídeo Pinacle Miro DC 30 plus ${ }^{5}$

As imagens foram capturadas em tamanho de 640 x 480 pixels, o que resulta em uma resolução espacial de 3 a 4 m no sobrevôo de $1500 \mathrm{~m}$ e de 6 a 8 m no sobrevôo de $3000 \mathrm{~m}$.

Segundo Um \& Wright (1999), a diferença de padrões de tamanho de pixel e resolução dos equipamentos é um dos motivos para a perda de resolução espacial e qualidade das imagens de vídeo digitalizadas.

Assim sendo, no sistema utilizado no trabalho, ocorreram perdas de resolução das câmeras para o gravador, e do gravador para a placa de captura que, segundo os autores acima, somente podem ser corrigidas com o desenvolvimento de câmeras digitais de alta resolução.

${ }^{5}$ PINACLE SYSTEMS. DC30 plus circuit board. Mountain View, 1997. 1p. 
A digitalização das imagens foi realizada capturando-se um pequeno filme de 30 quadros por segundo, contendo a área de estudo.

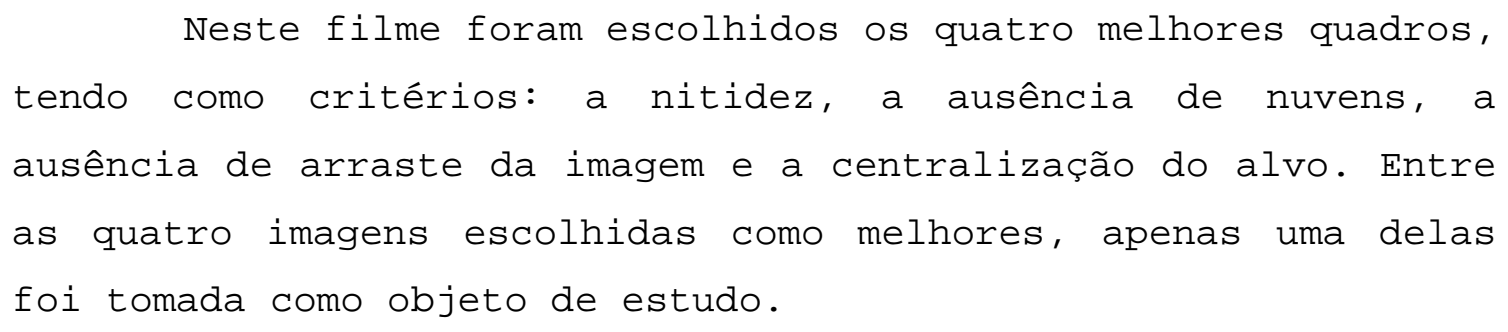

Neste filme foram escolhidos os quatro melhores quadros, tendo como critérios: a nitidez, a ausência de nuvens, a ausência de arraste da imagem e a centralização do alvo. Entre as quatro imagens escolhidas como melhores, apenas uma delas foi tomada como objeto de estudo.

Portanto, o trabalho de captura com duas câmeras, cada uma com quatro faixas do espectro, em duas altitudes, resultou em dezesseis imagens.

\section{6 Análise de pixel}

As dezesseis imagens capturadas tiveram os valores de pixels referentes à área útil de cada parcela dos tratamentos do experimento de omissão de nutrientes analisados determinando - comportamento dos valores, que podem variar de 0 até 255 . Os valores de pixel de cada imagem foram desmembrados e estudados nos espectros vermelho, verde e azul, separados pelo software ENVI 2.6, utilizado para a análise.

As áreas selecionadas referentes à área útil das
parcelas dos tratamentos foram denominadas regiões de
interesse.

Essas regiões de interesse foram definidas em cada uma das parcelas do experimento por meio de uma quadrícula inserida na imagem pelo programa Adobe Photoshop, depois de realizada a 
contagem das árvores, conforme exemplifica a Figura 9, visando com isto um erro mínimo na sua marcação (Figura 10).

$\mathrm{Na}$ análise dos valores dos pixels, dentro das regiões de interesse, foram obtidas as médias, o valor mínimo, o valor máximo e o desvio padrão dos valores de pixel de cada imagem.

Figura 9 - Quadrículas desenhadas conforme contagem de árvores

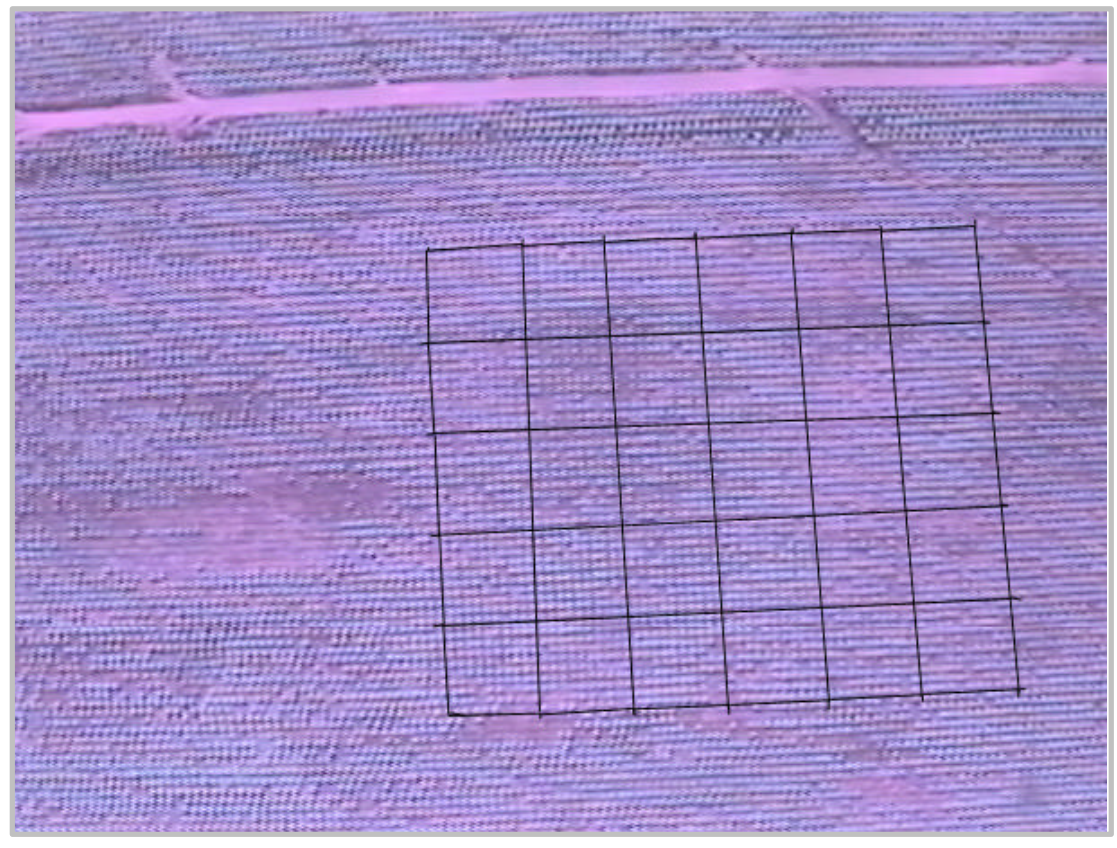

do experimento e utilizadas na orientação da marcação dos locais das regiões de interesse de onde foram extraídos os valores de pixel. 


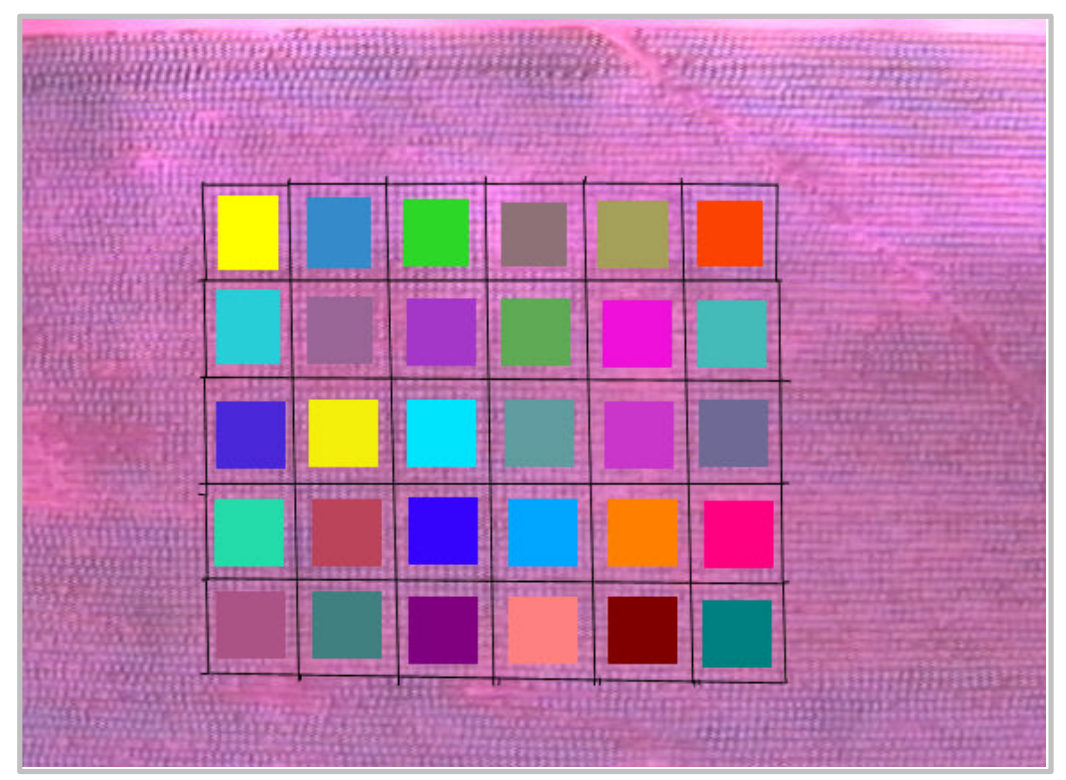

Figura 10 - Exemplificação das regiões de interesse definidas em cada imagem.

\subsection{Dados de campo}

\subsubsection{Dados dendrométricos}

Os dados dendrométricos medidos foram: diâmetro da planta a 1,30 m de altura, altura total da planta e área da projeção da copa.

As mensurações foram realizadas aos três e aos 10 meses de idade, sendo que na última, as medições foram feitas dois dias antes da realização do vôo para obtenção das imagens.

A altura das plantas e a área da projeção da copa foram medidas com uma régua e o diâmetro das plantas, com uma suta eletrônica. 
Os resultados das medições foram analisados, buscando relações entre produtividade e efeito dos tratamentos e produtividade e valores de pixel de cada imagem.

\subsubsection{Análises químicas}

Dois dias antes da obtenção das imagens foram coletadas amostras de material vegetal para análise de teor de nutrientes e amostras de solo para análise nutricional.

As amostras de material vegetal foram coletadas das seis plantas úteis diagonais da parcela, amostrando folhas maduras, da $3^{a}$ até a $7^{a}$ folha dos ramos da parte mediana da copa, nos lados da planta referentes aos quatro pontos cardeais (Malavolta et al., 1997).

As amostras de solo foram coletadas próximo das árvores utilizadas para a amostragem de folhas, totalizando seis pontos dentro da parcela. O total de pontos amostrados dentro da área do experimento foi de 180, nas profundidades de 0-20 cm e 20-40 $\mathrm{cm}$.

Tanto para análise de material vegetal como das amostras

de solo foram quantificados os teores de macro e micronutrientes. As determinações químicas foram realizadas pelo Departamento de Solos e Nutrição da ESALQ/USP. 


\title{
3.8 Relação dos dados de campo com as imagens
}

\author{
Os dados de campo foram comparados a fim de determinar \\ diferenças entre os tratamentos, através de análise de \\ variância e teste de comparação de médias. \\ Com os dados de campo, os teores dos nutrientes \\ estudados ( $N, \mathrm{P}, \mathrm{K}$ e $\mathrm{B}$ ) $\mathrm{e}$ os valores de pixel de cada \\ tratamento, repetição, imagem e espectro, foram realizadas \\ análises de regressão visando encontrar relações entre os \\ valores de pixel e dos dados dendrométricos, e entre os valores \\ de pixel e os teores de nutrientes. \\ Também foram realizadas análises de "Cluster" para \\ verificar os agrupamentos de imagens possíveis. \\ As análises estatísticas foram realizadas no software \\ SAS (Statistical Analysis System), SAS Institute Inc. (1988).
}




\section{RESULTADOS E DISCUSSÃO}

\subsection{Medição dos filtros utilizados}

Os filtros de subtração de faixas do espectro eletromagnético visível, uma vez montados conforme apresentado em material e métodos, tiveram sua transmitância medida em espectroradiômetro no Instituto Nacional de Pesquisas Espaciais - INPE, em São José dos Campos.

Confirmou-se com isto, a eficiência e a transparência dos filtros apenas na faixa do espectro a que se destinaram.

$$
\text { Os resultados das leituras realizadas para a aferição }
$$
estão apresentados graficamente nas Figuras 11, 12, 13 e 14 . 


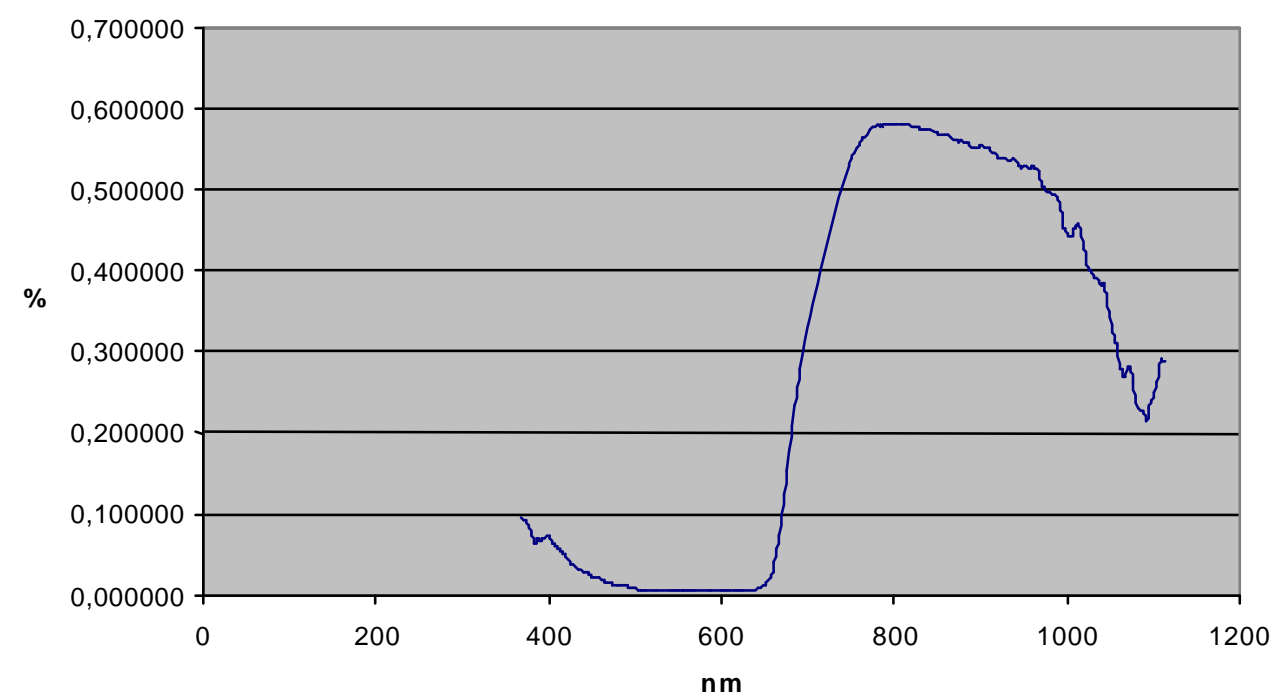

Figura 11 - Transmitância do filtro de transparência para a faixa azul do espectro eletromagnético.

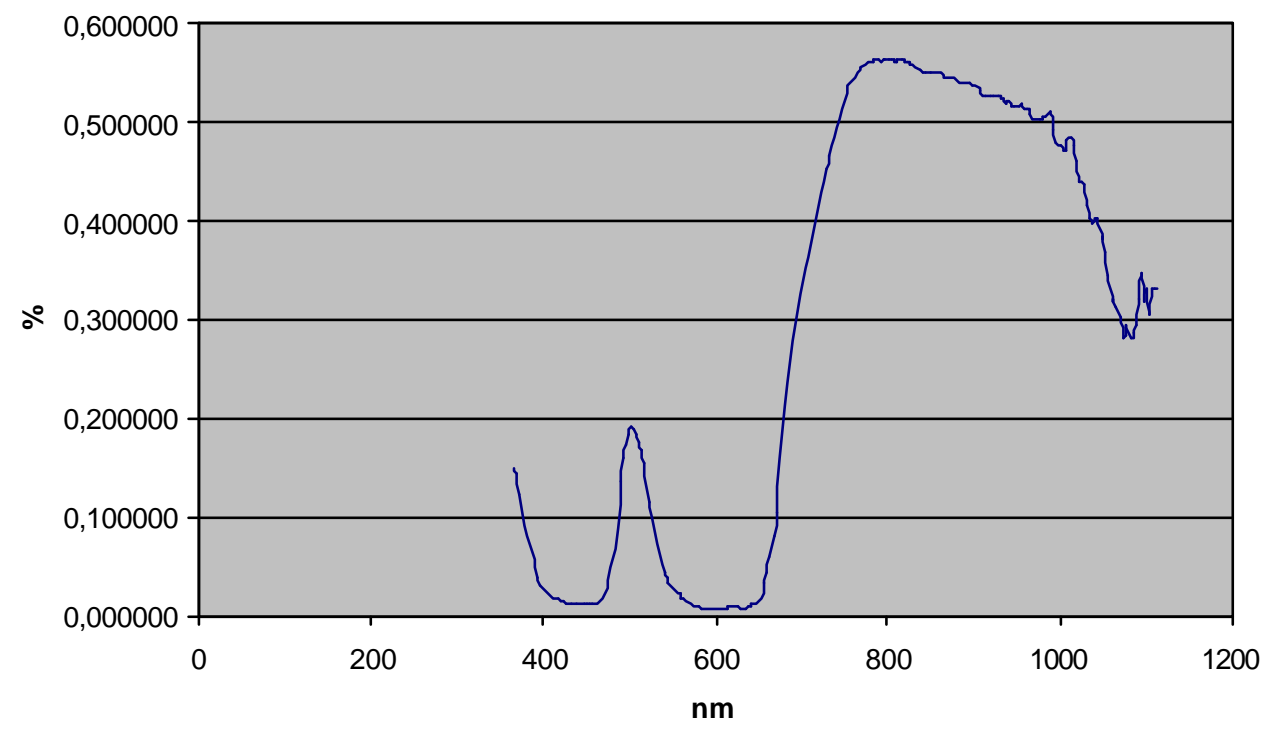

Figura 12 - Transmitância do filtro para transparência da faixa Verde do espectro eletromagnético. 


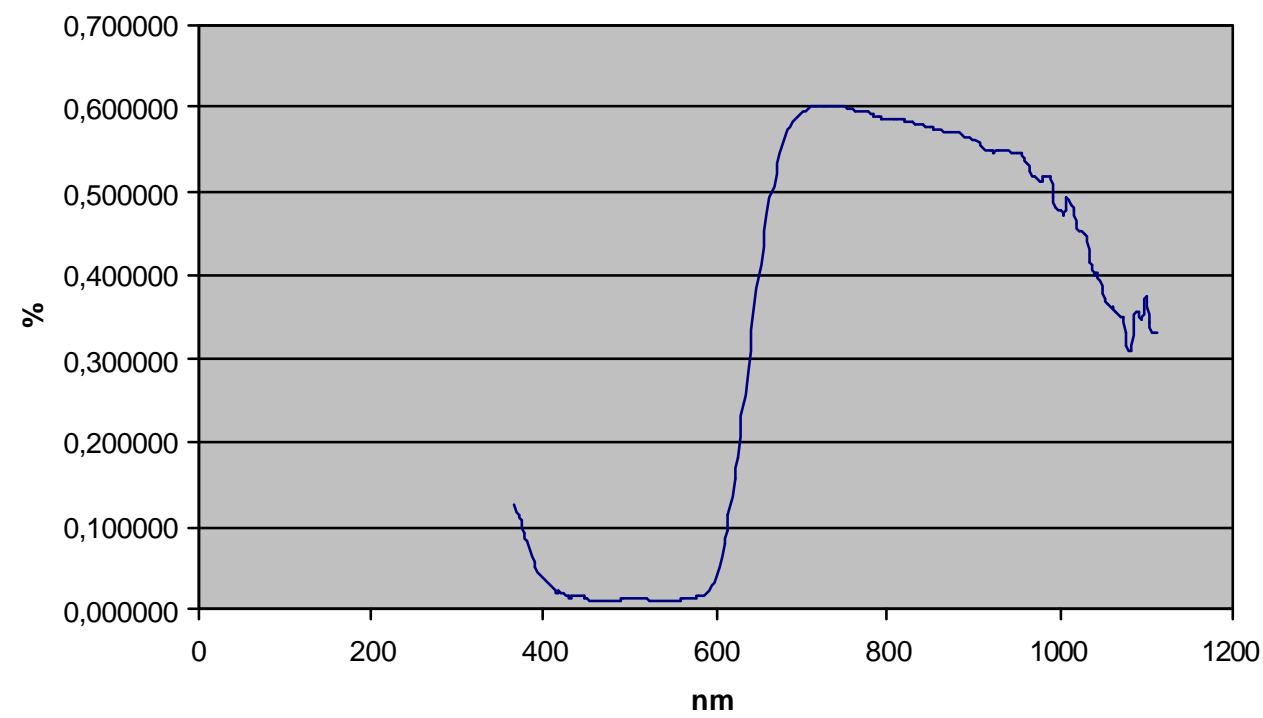

Figura 13 - Transmitância do filtro para transparência da faixa vermelho do espectro eletromagnético.

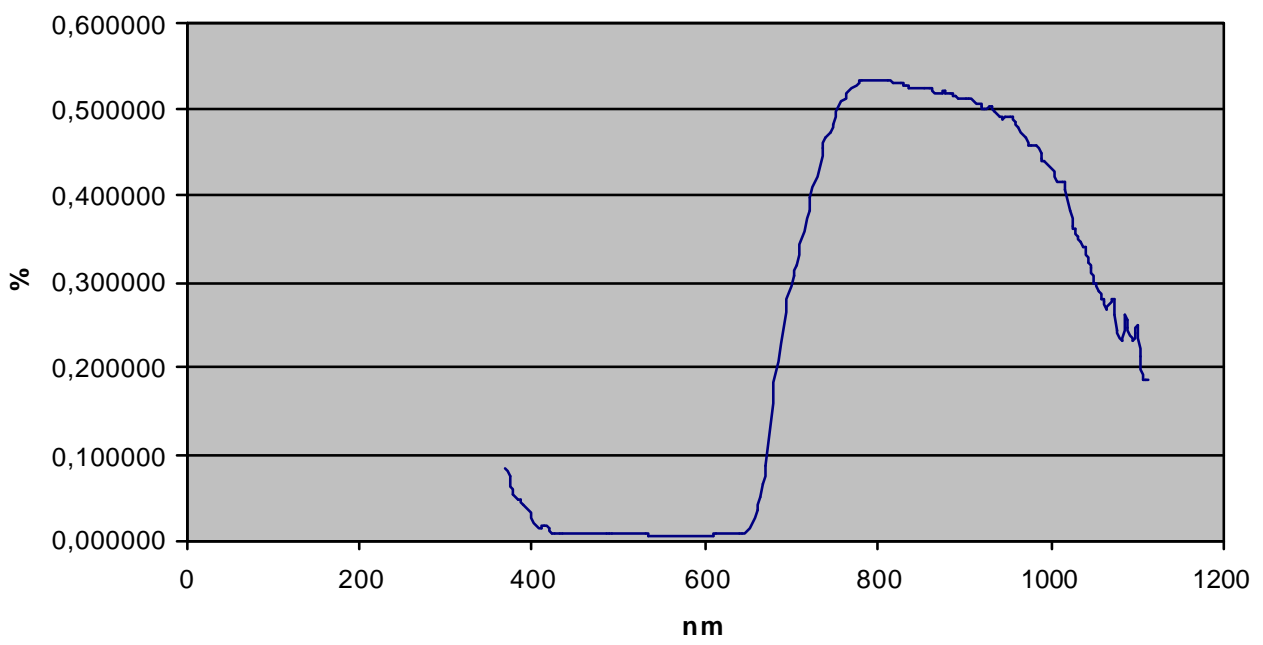

Figura 14 - Transmitância do filtro para transparência da faixa infravermelho próximo do espectro eletromagnético. 


\subsection{Análises químicas}

\subsubsection{Análise química do solo}

As amostras de solo foram analisadas pelo Laboratório de Análises Químicas do Departamento de Solos e Nutrição da ESALQ/USP, com o objetivo de se conhecer o nível de fertilidade do solo e verificar se havia variação entre as parcelas devido às características naturais do solo ou da adubação empregada.

Estas análises mostraram que os teores dos nutrientes no solo não variaram significativamente ao nível de probabilidade de 5\% entre as parcelas dos tratamentos. O solo foi considerado como de baixa fertilidade.

As Tabelas 5, 6 e 7 mostram os teores abaixo do
adequado, os valores médios e os valores considerados
adequados, conforme Malavolta et al. (1997) e em ANDA/POTAFOS
(1989).


Tabela 5. Resultados médios de pH, Matéria Orgânica (M.O.), fósforo (P), enxofre $\left(\mathrm{S}-\mathrm{SO}_{4}\right)$, potássio $(\mathrm{K})$, cálcio (Ca) e magnésio (Mg) nas parcelas dos tratamentos nas profundidades de $0-20 \mathrm{~cm}$ e $20-40 \mathrm{~cm}$.

\begin{tabular}{|c|c|c|c|c|c|c|c|c|}
\hline \multirow[t]{2}{*}{ Tratamento } & \multirow[t]{2}{*}{$\begin{array}{c}\text { Prof. } \\
\text { (cm) }\end{array}$} & \multirow[t]{2}{*}{$\mathrm{pH}$} & \multirow{2}{*}{$\begin{array}{l}\text { M.O. } \\
\text { g/dm }\end{array}$} & $\begin{array}{c}\text { P } \\
\text { (resina) }\end{array}$ & $\mathrm{S}-\mathrm{SO}_{4}$ & $\mathbf{K}$ & $\mathrm{Ca}$ & Mg \\
\hline & & & & \multicolumn{2}{|c|}{$\mathrm{mg} / \mathrm{dm}^{3}$} & \multicolumn{3}{|c|}{$\mathrm{mmol}_{\mathrm{c}} / \mathrm{dm}^{3}$} \\
\hline B & $0-20$ & $4,03^{1}$ & $16^{1}$ & $3,0^{1}$ & $2,0^{1}$ & $0,47^{1}$ & $3,0^{1}$ & $1,7^{1}$ \\
\hline B & $20-40$ & $3,80^{1}$ & $11^{1}$ & $2,0^{1}$ & $3,3^{1}$ & $0,47^{1}$ & $1,7^{1}$ & $1,3^{1}$ \\
\hline $\mathrm{KB}$ & $0-20$ & $3,80^{1}$ & $16^{1}$ & $2,3^{1}$ & $3,0^{1}$ & $0,37^{1}$ & $1,3^{1}$ & $1,3^{1}$ \\
\hline $\mathrm{KB}$ & $20-40$ & $3,77^{1}$ & $11^{1}$ & $1,3^{1}$ & $2,7^{1}$ & $0,27^{1}$ & $1,0^{1}$ & $1,0^{1}$ \\
\hline NADA & $0-20$ & $3,90^{1}$ & $16^{1}$ & $2,3^{1}$ & $2,3^{1}$ & $0,50^{1}$ & $3,7^{1}$ & $1,3^{1}$ \\
\hline NADA & $20-40$ & $3,93^{1}$ & $11^{1}$ & $1,7^{1}$ & $2,3^{1}$ & $0,40^{1}$ & $1,0^{1}$ & $1,0^{1}$ \\
\hline NB & $0-20$ & $3,80^{1}$ & $15^{1}$ & $2,3^{1}$ & $2,7^{1}$ & $0,43^{1}$ & $1,7^{1}$ & $1,0^{1}$ \\
\hline NB & $20-40$ & $3,80^{1}$ & $13^{1}$ & $1,0^{1}$ & $3,7^{1}$ & $0,37^{1}$ & $1,0^{1}$ & $1,0^{1}$ \\
\hline NKB & $0-20$ & $3,77^{1}$ & $16^{1}$ & $1,7^{1}$ & $2,0^{1}$ & $0,43^{1}$ & $2,3^{1}$ & $1,7^{1}$ \\
\hline NKB & $20-40$ & $3,77^{1}$ & $12^{1}$ & $1,0^{1}$ & $3,3^{1}$ & $0,47^{1}$ & $1,0^{1}$ & $1,0^{1}$ \\
\hline NPB & $0-20$ & $3,77^{1}$ & $15^{1}$ & $2,3^{1}$ & $3,3^{1}$ & $0,37^{1}$ & $2,0^{1}$ & $2,0^{1}$ \\
\hline NPB & $20-40$ & $3,77^{1}$ & $13^{1}$ & $3,0^{1}$ & $3,3^{1}$ & $0,33^{1}$ & $3,7^{1}$ & $1,7^{1}$ \\
\hline NPK & $0-20$ & $3,77^{1}$ & $16^{1}$ & $2,7^{1}$ & $2,7^{1}$ & $0,40^{1}$ & $3,0^{1}$ & $1,3^{1}$ \\
\hline NPK & $20-40$ & $3,83^{1}$ & $10^{1}$ & $2,0^{1}$ & $3,7^{1}$ & $0,30^{1}$ & $1,0^{1}$ & $1,0^{1}$ \\
\hline NP KB & $0-20$ & $3,87^{1}$ & $15^{1}$ & $3,0^{1}$ & $2,0^{1}$ & $0,53^{1}$ & $2,3^{1}$ & $1,0^{1}$ \\
\hline NP KB & $20-40$ & $3,93^{1}$ & $8^{1}$ & $1,3^{1}$ & $3,0^{1}$ & $0,33^{1}$ & $1,3^{1}$ & $1,0^{1}$ \\
\hline $\mathrm{PB}$ & $0-20$ & $3,93^{1}$ & $14^{1}$ & $2,0^{1}$ & $2,3^{1}$ & $0,50^{1}$ & $1,3^{1}$ & $1,0^{1}$ \\
\hline $\mathrm{PB}$ & $20-40$ & $3,87^{1}$ & $11^{1}$ & $1,3^{1}$ & $3,7^{1}$ & $0,37^{1}$ & $1,0^{1}$ & $1,0^{1}$ \\
\hline $\mathrm{PKB}$ & $0-20$ & $3,80^{1}$ & $18^{1}$ & 2,7 & $2,7^{1}$ & $0,50^{1}$ & $2,3^{1}$ & $1,0^{1}$ \\
\hline $\mathrm{PKB}$ & $20-40$ & $3,80^{1}$ & $12^{1}$ & $1,3^{1}$ & $2,7^{1}$ & $0,30^{1}$ & $1,0^{1}$ & $1,0^{1}$ \\
\hline
\end{tabular}


Tabela 6. Resultados médios de acidez potencial (H $+A l)$, soma de bases (SB), CTC efetiva ( $T$ ), saturação de bases (V) e saturação de alumínio (M) nas profundidades de $0-20 \mathrm{~cm}$ e $20-40 \mathrm{~cm}$.

\begin{tabular}{|c|c|c|c|c|c|c|}
\hline \multirow{2}{*}{ Tratamento } & \multirow{2}{*}{$\begin{array}{l}\text { Profundidade } \\
\qquad(\mathrm{cm})\end{array}$} & $\mathrm{H}+\mathrm{Al}$ & $\mathrm{SB}$ & $\mathrm{T}$ & V & M \\
\hline & & \multicolumn{3}{|c|}{$\mathrm{Mmol}_{\mathrm{c}} / \mathrm{dm}^{3}$} & \multicolumn{2}{|c|}{$\%$} \\
\hline B & $0-20$ & $37,3^{2}$ & $5,1^{1}$ & $42,4^{2}$ & $12,0^{1}$ & $61,7^{1}$ \\
\hline B & $20-40$ & $28,0^{2}$ & $3,4^{1}$ & $31,4^{2}$ & $11,0^{1}$ & $72,3^{1}$ \\
\hline $\mathrm{KB}$ & $0-20$ & $37,3^{2}$ & $3,0^{1}$ & $30,3^{2}$ & $7,7^{1}$ & $77,3^{1}$ \\
\hline $\mathrm{KB}$ & $20-40$ & $28,0^{2}$ & $2,2^{1}$ & $30,2^{2}$ & $7,3^{1}$ & $80,3^{1}$ \\
\hline NADA & $0-20$ & $40,0^{2}$ & $5,5^{1}$ & $43,5^{2}$ & $12,7^{1}$ & $63,7^{1}$ \\
\hline NADA & $20-40$ & $27,0^{2}$ & $2,4^{1}$ & $29,4^{2}$ & $8,3^{1}$ & $78,3^{1}$ \\
\hline NB & $0-20$ & $35,3^{2}$ & $3,1^{1}$ & $38,4^{2}$ & $7,7^{1}$ & $79,0^{1}$ \\
\hline NB & $20-40$ & $29,0^{2}$ & $2,3^{1}$ & $31,3^{2}$ & $7,3^{1}$ & $80,3^{1}$ \\
\hline $\mathrm{NKB}$ & $0-20$ & $38,0^{2}$ & $4,4^{1}$ & $42,4^{2}$ & $10,3^{1}$ & $70,0^{1}$ \\
\hline NKB & $20-40$ & $28,0^{2}$ & $2,4^{1}$ & $30,4^{2}$ & $8,3^{1}$ & $78,7^{1}$ \\
\hline NPB & $0-20$ & $36,6^{2}$ & $4,3^{1}$ & $41,0^{2}$ & $10,3^{1}$ & $71,7^{1}$ \\
\hline NPB & $20-40$ & $32,6^{2}$ & $5,6^{1}$ & $38,3^{2}$ & $12,7^{1}$ & $69,3^{1}$ \\
\hline NPK & $0-20$ & $37,6^{2}$ & $4,7^{1}$ & $42,4^{2}$ & $11,3^{1}$ & $70,7^{1}$ \\
\hline NPK & $20-40$ & $28,0^{2}$ & $2,3^{1}$ & $30,3^{2}$ & $7,7^{1}$ & $79,0^{1}$ \\
\hline NP KB & $0-20$ & $37,0^{2}$ & $3,8^{1}$ & $40,8^{2}$ & $9,3^{1}$ & $71,3^{1}$ \\
\hline $\mathrm{NPKB}$ & $20-40$ & $25,0^{1}$ & $2,6^{1}$ & $27,6^{2}$ & $9,3^{1}$ & $76,0^{1}$ \\
\hline $\mathrm{PB}$ & $0-20$ & $34,6^{2}$ & $2,8^{1}$ & $37,5^{2}$ & $7,7^{1}$ & $77,7^{1}$ \\
\hline $\mathrm{PB}$ & $20-40$ & $27,0^{2}$ & $2,3^{1}$ & $28,3^{2}$ & $8,3^{1}$ & $79,3^{1}$ \\
\hline $\mathrm{PKB}$ & $0-20$ & $42,6^{2}$ & $3,8^{1}$ & $46,5^{2}$ & $8,7^{1}$ & $72,3^{1}$ \\
\hline PKB & $20-40$ & $27,0^{2}$ & $2,3^{1}$ & $29,3^{2}$ & $7,7^{1}$ & $80,3^{1}$ \\
\hline
\end{tabular}


Tabela 7. Resultados médios do teor dos micronutrientes boro (B), cobre $(\mathrm{Cu})$, ferro (Fe), manganês $(\mathrm{Mn})$ e zinco $(\mathrm{Zn})$ nas parcelas dos tratamentos nas profundidades de $0-20 \mathrm{~cm}$ e $20-40 \mathrm{~cm}$.

\begin{tabular}{|c|c|c|c|c|c|c|}
\hline \multirow{2}{*}{ Tratamento } & \multirow{2}{*}{$\begin{array}{l}\text { Profundidade } \\
\qquad(\mathrm{cm})\end{array}$} & B & $\mathrm{Cu}$ & $\mathrm{Fe}$ & $\mathrm{Mn}$ & $\mathrm{Zn}$ \\
\hline & & \multicolumn{5}{|c|}{$\mathrm{mg} / \mathrm{dm}^{3}$} \\
\hline B & $0-20$ & $0,3^{2}$ & $0,17^{1}$ & $59,0^{3}$ & $2,57^{1}$ & $0,33^{1}$ \\
\hline B & $20-40$ & $0,3^{2}$ & $0,10^{1}$ & $36,3^{3}$ & $1,00^{1}$ & $0,23^{1}$ \\
\hline $\mathrm{KB}$ & $0-20$ & $0,4^{3}$ & $0,13^{1}$ & $62,7^{3}$ & $1,97^{1}$ & $0,43^{1}$ \\
\hline $\mathrm{KB}$ & $20-40$ & $0,3^{2}$ & $0,10^{1}$ & $39,3^{3}$ & $0,63^{1}$ & $0,20^{1}$ \\
\hline NADA & $0-20$ & $0,3^{2}$ & $0,13^{1}$ & $74,7^{3}$ & $3,30^{2}$ & $0,57^{2}$ \\
\hline NADA & $20-40$ & $0,3^{2}$ & $0,10^{1}$ & $41,3^{3}$ & $0,67^{1}$ & $0,20^{1}$ \\
\hline NB & $0-20$ & $0,3^{2}$ & $0,13^{1}$ & $74,0^{3}$ & $1,70^{1}$ & $0,30^{1}$ \\
\hline NB & $20-40$ & $0,3^{2}$ & $0,10^{1}$ & $51,0^{3}$ & $0,43^{1}$ & $0,20^{1}$ \\
\hline $\mathrm{NKB}$ & $0-20$ & $0,3^{2}$ & $0,13^{1}$ & $68,3^{3}$ & $1,80^{1}$ & $0,33^{1}$ \\
\hline NKB & $20-40$ & $0,3^{2}$ & $0,13^{1}$ & $42,0^{3}$ & $0,67^{1}$ & $0,23^{1}$ \\
\hline NPB & $0-20$ & $0,4^{3}$ & $0,13^{1}$ & $65,0^{3}$ & $1,73^{1}$ & $0,30^{1}$ \\
\hline NPB & $20-40$ & $0,3^{2}$ & $0,17^{1}$ & $59,0^{3}$ & $1,70^{1}$ & $0,23^{1}$ \\
\hline NPK & $0-20$ & $0,3^{2}$ & $0,20^{1}$ & $72,7^{3}$ & $2,90^{1}$ & $0,37^{1}$ \\
\hline NPK & $20-40$ & $0,3^{2}$ & $0,13^{1}$ & $38,0^{3}$ & $0,83^{1}$ & $0,23^{1}$ \\
\hline NPKB & $0-20$ & $0,4^{3}$ & $0,20^{1}$ & $71,3^{3}$ & $3,07^{1}$ & $0,43^{1}$ \\
\hline $\mathrm{NPKB}$ & $20-40$ & $0,3^{2}$ & $0,13^{1}$ & $37,7^{3}$ & $0,53^{1}$ & $0,23^{1}$ \\
\hline $\mathrm{PB}$ & $0-20$ & $0,3^{2}$ & $0,17^{1}$ & $59,3^{3}$ & $1,57^{1}$ & $0,30^{1}$ \\
\hline $\mathrm{PB}$ & $20-40$ & $0,4^{3}$ & $0,13^{1}$ & $39,0^{3}$ & $0,87^{1}$ & $0,27^{1}$ \\
\hline $\mathrm{PKB}$ & $0-20$ & $0,3^{2}$ & $0,13^{1}$ & $78,0^{3}$ & $3,13^{2}$ & $0,30^{1}$ \\
\hline $\mathrm{PKB}$ & $20-40$ & $0,3^{2}$ & $0,10^{1}$ & $43,7^{3}$ & $0,43^{1}$ & $0,20^{1}$ \\
\hline
\end{tabular}

${ }^{1}$ valores inadequados ${ }^{2}$ Valores médios ${ }^{3}$ valores adequados (Malavolta et al., 1997; ANDA/POTAFOS, 1989). 
Os baixos teores de nutrientes no solo indicaram a predisposição do sítio em induzir deficiências nos tratamentos com omissão de nutrientes.

O micronutriente boro foi o único dos nutrientes estudados cujos teores existentes no solo não foram considerados baixos, provavelmente devido à presença de restos vegetais do cultivo anterior, ainda em decomposição (Malavolta et al., 1997).

\subsubsection{Análise química do material vegetal}

A análise de material vegetal foi realizada para comprovar a existência de deficiência nutricional nos tratamentos de omissão dos nutrientes estudados no experimento.

Os teores de nutrientes encontrados no experimento foram comparados e analisados com dados publicados por Malavolta et al. (1997) e Dell et al. (1995), os quais estabeleceram os níveis como sendo deficiente, adequado e médios de macronutrientes e micronutrientes, em folhas de eucalipto (Tabelas 8 e 9). 
Tabela 8. Teores de Macronutrientes encontrados nas folhas das

\begin{tabular}{ccccccc}
\multicolumn{6}{c}{ plantas nos tratamentos estudados. } \\
\cline { 2 - 7 } & $\mathrm{N}$ & $\mathrm{P}$ & $\mathrm{K}$ & $\mathrm{Ca}$ & $\mathrm{Mg}$ & $\mathrm{S}$ \\
\hline $\mathrm{c}$ B $\mathrm{kg}^{1}$ \\
$\mathrm{~N}$ & $18,57^{2}$ & $0,87^{2}$ & $4,17^{1}$ & $6,73^{3}$ & $2,43^{2}$ & $1,20^{2}$ \\
$\mathrm{~KB}$ & $21,07^{2}$ & $0,90^{2}$ & $8,87^{2}$ & $5,50^{3}$ & $1,83^{1}$ & $1,07^{2}$ \\
$\mathrm{NADA}$ & $19,37^{2}$ & $0,97^{2}$ & $4,40^{1}$ & $6,60^{3}$ & $2,63^{2}$ & $1,23^{2}$ \\
$\mathrm{NB}$ & $20,84^{2}$ & $0,96^{2}$ & $4,33^{1}$ & $6,20^{3}$ & $2,33^{2}$ & $1,47^{2}$ \\
$\mathrm{NKB}$ & $19,87^{2}$ & $0,83^{2}$ & $5,90^{1}$ & $5,30^{3}$ & $1,67^{1}$ & $1,23^{2}$ \\
$\mathrm{NPB}$ & $22,00^{2}$ & $1,07^{2}$ & $5,03^{1}$ & $5,97^{3}$ & $1,93^{1}$ & $1,33^{2}$ \\
$\mathrm{NPK}$ & $20,30^{2}$ & $0,83^{2}$ & $4,93^{1}$ & $5,67^{3}$ & $1,73^{1}$ & $1,26^{2}$ \\
$\mathrm{NPKB}$ & $21,20^{2}$ & $0,97^{2}$ & $5,63^{1}$ & $5,20^{3}$ & $1,93^{1}$ & $1,37^{2}$ \\
$\mathrm{~PB}$ & $20,44^{2}$ & $0,96^{2}$ & $4,13^{1}$ & $5,97^{3}$ & $2,30^{2}$ & $1,37^{2}$ \\
$\mathrm{PKB}$ & $20,17^{2}$ & $0,93^{2}$ & $5,80^{1}$ & $5,80^{3}$ & $1,67^{1}$ & $1,20^{2}$
\end{tabular}

${ }^{1}$ Valores deficientes; ${ }^{2}$ Valores médios; ${ }^{3}$ Valores adequados (Malavolta et al., 1997; Dell et al., 1995).

Dentre os macronutrientes estudados o potásio (K) apresentou teores abaixo do adequado até mesmo nos tratamentos onde não houve sua omissão. Esta situação é descrita por Barros (1990), que cita o potássio como um elemento limitante à produtividade do eucalipto, principalmente em solos onde ele não está contido nos minerais de formação, como a areia quartzosa. 
Tabela 9. Teores de Micronutrientes encontrados nas folhas das plantas nos tratamentos estudados.

\begin{tabular}{cccccc}
\hline \multicolumn{7}{c}{$\mathrm{B}$} & $\mathrm{Cu}$ & $\mathrm{Fe}$ & $\mathrm{Mn}$ & $\mathrm{Zn}$ \\
\hline $\mathrm{B}$ & $62,67^{3}$ & $6,33^{2}$ & $269,67^{3}$ & $734,33^{3}$ & $13,67^{1}$ \\
$\mathrm{~KB}$ & $48,67^{3}$ & $6,33^{2}$ & $316,67^{3}$ & $721,33^{3}$ & $14,00^{1}$ \\
$\mathrm{NADA}$ & $18,33^{1}$ & $5,33^{1}$ & $276,30^{3}$ & $602,33^{3}$ & $13,33^{1}$ \\
$\mathrm{NB}$ & $60,00^{3}$ & $6,33^{2}$ & $291,33^{3}$ & $691,67^{3}$ & $13,67^{1}$ \\
$\mathrm{NKB}$ & $62,67^{3}$ & $5,00^{1}$ & $312,33^{3}$ & $601,67^{3}$ & $12,67^{1}$ \\
$\mathrm{NPB}$ & $42,33^{3}$ & $9,33^{3}$ & $300,67^{3}$ & $876,33^{3}$ & $14,33^{1}$ \\
$\mathrm{NPK}$ & $15,67^{1}$ & $4,33^{1}$ & $315,33^{3}$ & $751,00^{3}$ & $12,00^{1}$ \\
$\mathrm{NPKB}$ & $115,00^{3}$ & $5,33^{1}$ & $309,00^{3}$ & $608,00^{3}$ & $12,33^{1}$ \\
$\mathrm{~PB}$ & $46,00^{3}$ & $5,00^{1}$ & $326,33^{3}$ & $639,00^{3}$ & $12,67^{1}$ \\
$\mathrm{PKB}$ & $50,67^{3}$ & $4,33^{1}$ & $295,00^{3}$ & $717,67^{3}$ & $11,33^{1}$
\end{tabular}

${ }^{1}$ Valores deficientes; ${ }^{2}$ Valores médios; ${ }^{3}$ Valores adequados (Malavolta et al., 1997; Dell et al., 1995).

Os valores dos teores nutricionais foram analisados estatisticamente constatando-se que, entre os nutrientes estudados, apenas os tratamentos NADA e NPK apresentaram diferenças significativas ao nível de 5\% de probabilidade dos demais tratamentos.

O tratamento com maior teor de boro foi o completo (NPKB), sendo significativamente diferente dos demais. Abaixo do tratamento NPKB estão os tratamentos $B$ e $N K B$, significativamente diferentes dos demais e semelhantes estatisticamente entre si.

O tratamento com o menor teor de boro foi o NPK, significativamente diferente dos demais tratamentos. Mesmo com os baixos teores de boro apresentados, não foram detectados 
sintomas visuais da deficiência deste micronutriente no tratamento NPK.

Segundo Malavolta et al. (1997) e Epstein (1975), as principais causas das deficiências de boro são: solos pobres em matéria orgânica, chuva ou seca em excesso e alto teor de nitrogênio na adubação.

O balanço hídrico do local do experimento, apresentado na Figura 15, mostra que se iniciava um período de déficit hídrico na região, o que pode ter acentuado a deficiência do nutriente, que é imóvel no solo (Malavolta et al., 1997).

Ainda no tratamento NPK, os baixos teores de boro também pode ter ocorrido por influência de uma "diluição" do nutriente, acarretada pelo crescimento vigoroso da planta.

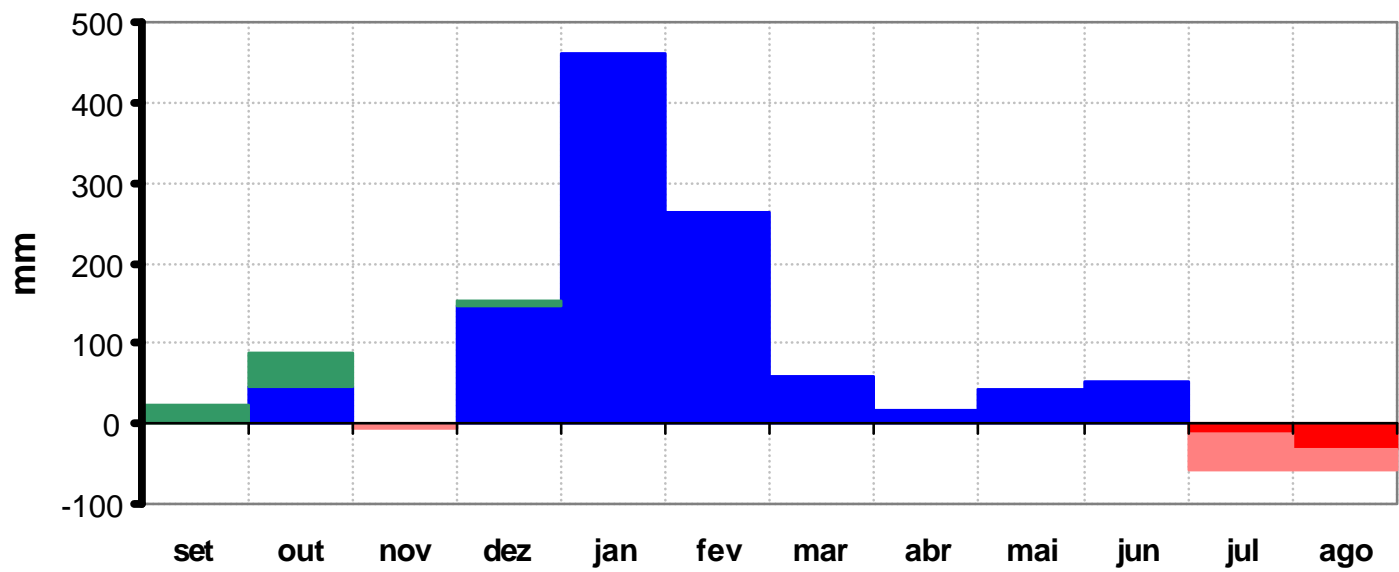

Deficiência $\square$ Excedente Retirada

Figura 15 - Deficiência, excedente, retirada e reposição hídrica da região de Brotas, durante o período do experimento. 


\subsection{Agrupamento de tratamentos conforme teor dos nutrientes nas} folhas

Os dados de teores nutricionais foram tabulados e
analisados através da Estatistica Multivariada, pelo método de
Cluster ou "Agrupamento" pela distância Euclidiana, conforme
descrito por Hair et al. (1998) e Valentini et al. (1995).
A análise de cluster consiste basicamente em agrupar os
tratamentos conforme a proximidade dos fatores mensurados, como
por exemplo, diâmetro, altura, teor de nutrientes, etc.
A análise de agrupamentos foi empregada para decidir se
dos nutrientes estudados nas análises dos valores das imagens.
os tratamentos foram agrupados conforme o teor de
nutrientes nas folhas, visando juntar os tratamentos conforme
os efeitos dos nutrientes como um todo. os agrupamentos obtidos
estão apresentados nas Figuras 16 e 17 .




\section{Similaridade}

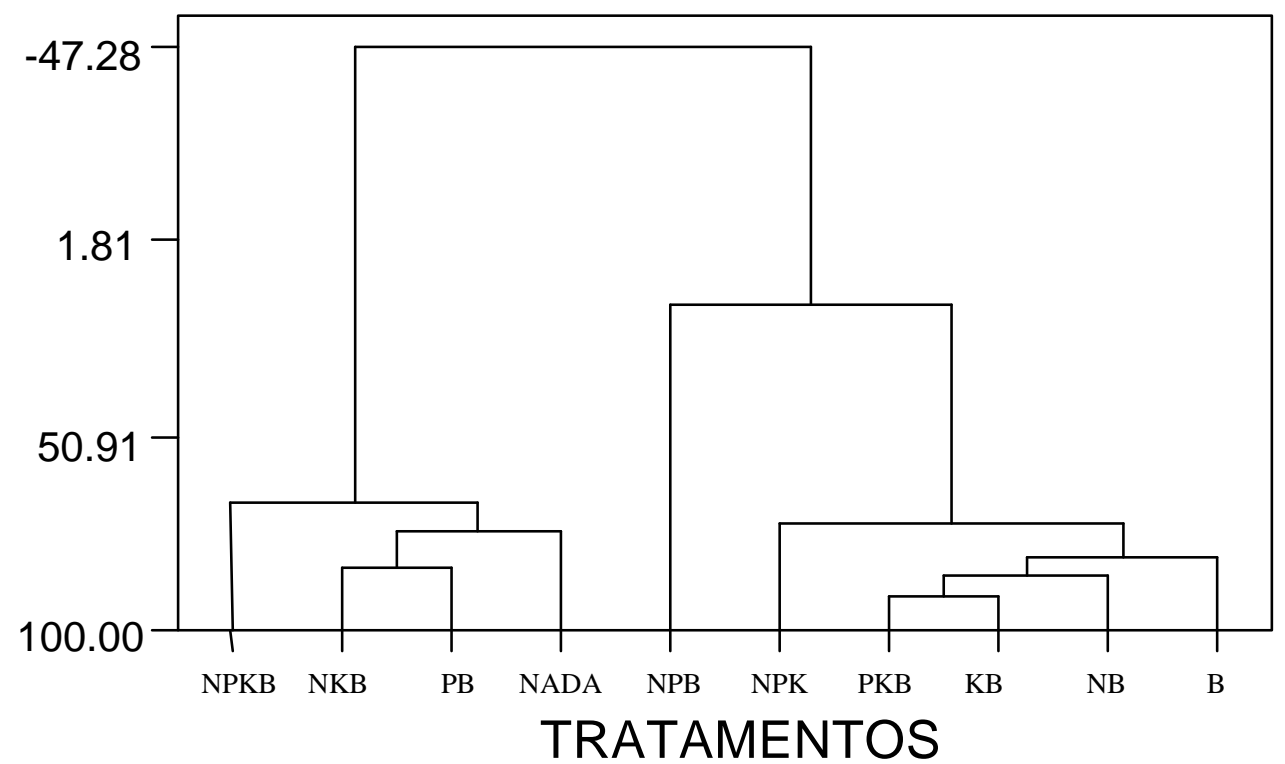

Figura 16 - Agrupamento dos tratamentos em razão do teor de nutrientes nas plantas, considerando todos os nutrientes analisados.

Observa-se na Figura 16 que os agrupamentos formados pelos teores de todos os nutrientes não foram coerentes, agrupando em um mesmo bloco, o tratamento completo e o tratamento com omissão de nitrogênio (N), fósforo (P), potásisio (K) e boro (B), que foram, respectivamente, os que apresentaram maior e menor produtividade. 


\section{Similaridade}

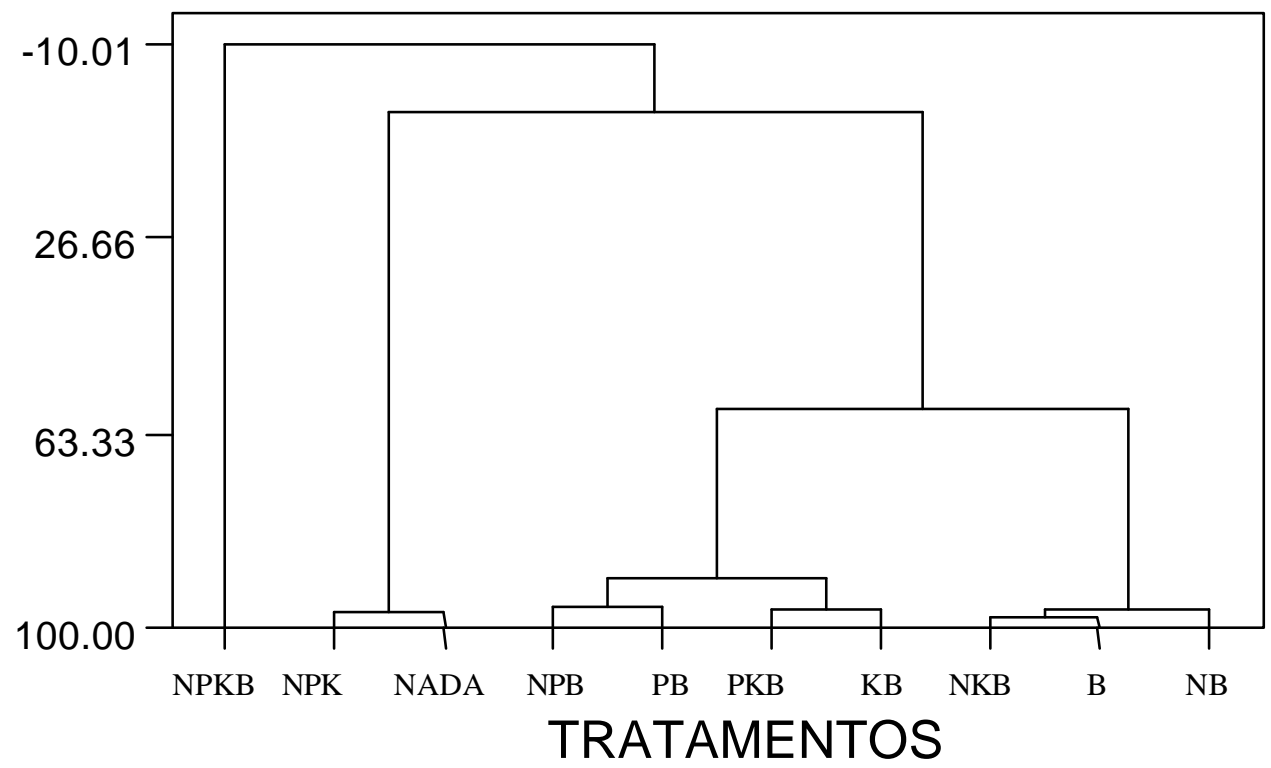

Figura 17 - Agrupamento dos tratamentos em razão do teor de nutrientes nas plantas, considerando os nutrientes nitrogênio (N), fósforo (P), potássio (K) e boro (B) .

Os agrupamentos formados apenas pelos teores de nitrogênio (N), fósforo (P), potássio (K) e boro (B), que foram os nutrientes estudados, mostraram um comportamento mais coerente do ponto de vista nutricional (Figura 17), formando quatro grupos:

- um grupo constituído apenas pelo tratamento completo (NPKB), onde os teores dos nutrientes foram mais altos;

- um grupo formado pelos tratamentos com omissão de boro (NPK) e sem aplicação de nutrientes (NADA);

- outro com os tratamentos com NPB, PB PKB e KB e;

- um último grupo com os tratamentos NKB, B e NB. 
o agrupamento dos tratamentos NADA e NPK, com crescimentos distintos conforme apresentado na Tabela 10, pode ser explicado pelo efeito de diluição dos nutrientes na planta, onde plantas com taxas distintas de crescimento podem ter teores de nutrientes semelhantes. Nota-se, entretanto, que estes tratamentos foram os únicos a apresentarem teores deficientes de boro nas folhas, e também os únicos tratamentos com a omissão deste nutriente.

Tabela 10. Análise dos parâmetros dendrométricos.

\begin{tabular}{|c|c|c|c|c|c|c|c|c|}
\hline \multicolumn{9}{|c|}{ Parâmetros Dendrométricos Analisados } \\
\hline \multicolumn{3}{|c|}{ Diâmetro } & \multicolumn{3}{|c|}{ Altura } & \multicolumn{3}{|c|}{ Área da Copa } \\
\hline $\begin{array}{c}\text { Tratament } \\
0 \\
\end{array}$ & $\begin{array}{r}\mathrm{DAP}^{*} \\
(\end{array}$ & $\begin{array}{l}\text { Médio } \\
\text { (cm) }\end{array}$ & $\begin{array}{c}\text { Tratament } \\
0\end{array}$ & $\begin{array}{r}\text { Altura } \\
(\mathrm{cr}\end{array}$ & $\begin{array}{l}\text { Média } \\
\text { m) }\end{array}$ & $\begin{array}{l}\text { Trata } \\
\text { mento }\end{array}$ & $\begin{array}{r}\text { Área } \\
\text { (r }\end{array}$ & $\begin{array}{l}\text { Média } \\
\mathrm{m}^{2} \text { ) }\end{array}$ \\
\hline NPK & 6,68 & a & NPK & 293,9 a & & NPK & 4,30 & a \\
\hline $\mathrm{NPKB}$ & 6,64 & a & $\mathrm{NPKB}$ & $281,5 \mathrm{ab}$ & & $\mathrm{NPKB}$ & 4,22 & $\mathrm{ab}$ \\
\hline PKB & 6,06 & $a b$ & PKB & 278,2 ab & $\mathrm{bc}$ & PKB & 3,82 & $a b$ \\
\hline NPB & 5,46 & $\mathrm{bc}$ & NPB & 257,4 & $\mathrm{bcd}$ & $\mathrm{PB}$ & 3,60 & $\mathrm{bc}$ \\
\hline $\mathrm{PB}$ & 5,34 & $\mathrm{bc}$ & $\mathrm{PB}$ & 249,4 & cde & $\mathrm{NKB}$ & 3,56 & $\mathrm{bc}$ \\
\hline $\mathrm{NKB}$ & 4,69 & $\mathrm{~cd}$ & $\mathrm{NKB}$ & 245,4 & def & $\mathrm{NPB}$ & 3,50 & $\mathrm{~cd}$ \\
\hline B & 4,11 & de & B & 222,8 & ef & B & 3,29 & $\mathrm{~cd}$ \\
\hline $\mathrm{KB}$ & 3,74 & de & NB & 217,7 & $\mathrm{fg}$ & NB & 3,28 & $\mathrm{~cd}$ \\
\hline NB & 3,73 & $\mathrm{de}$ & NADA & 212,1 & $g$ & $\mathrm{~KB}$ & 3,04 & de \\
\hline NADA & 3,06 & e & $\mathrm{KB}$ & 209,7 & 9 & NADA & 2,75 & e \\
\hline
\end{tabular}

* DAP - diâmetro do caule a $1,3 \mathrm{~m}$ do solo.

\subsection{Análises dendrométricas}

Foram medidos o diâmetro, altura e área da copa das árvores úteis das parcelas do experimento. Os valores médios dos parâmetros estudados e os tratamentos que diferiram 
significativamente ao nível de 5\% de probabilidade estão apresentados na Tabela 10 .

Para todos os parâmetros dendrométricos os tratamentos apresentaram uma seqüência semelhante, o que mostra um efeito dos tratamentos no crescimento das plantas, embora os teores dos nutrientes nas folhas não tenham se apresentado deficientes, com exceção do potássio, que apresentou teores inadequados em todos os tratamentos, exceto no tratamento KB.

O tratamento NPK foi o que apresentou maior crescimento, porém, não significativamente diferente do tratamento NPKB.

Os piores tratamentos foram o de omissão de todos os nutrientes (NADA) e o que foi aplicado apenas K (potássio) e B (boro) .

Os dados das avaliações dendrométricas, assim como os teores de nutrientes estudados nas folhas, foram agrupados pelo método de cluster.

$\mathrm{Na}$ Figura 18 podemos observar $\circ$ agrupamento de tratamentos, conforme os dados dendrométricos.

Nos agrupamentos obtidos pela análise de Cluster, os grupos indicaram coerência quando comparados com a ordenação promovida pelo teste de Tukey (Tabela 10). 


\section{Similaridade}

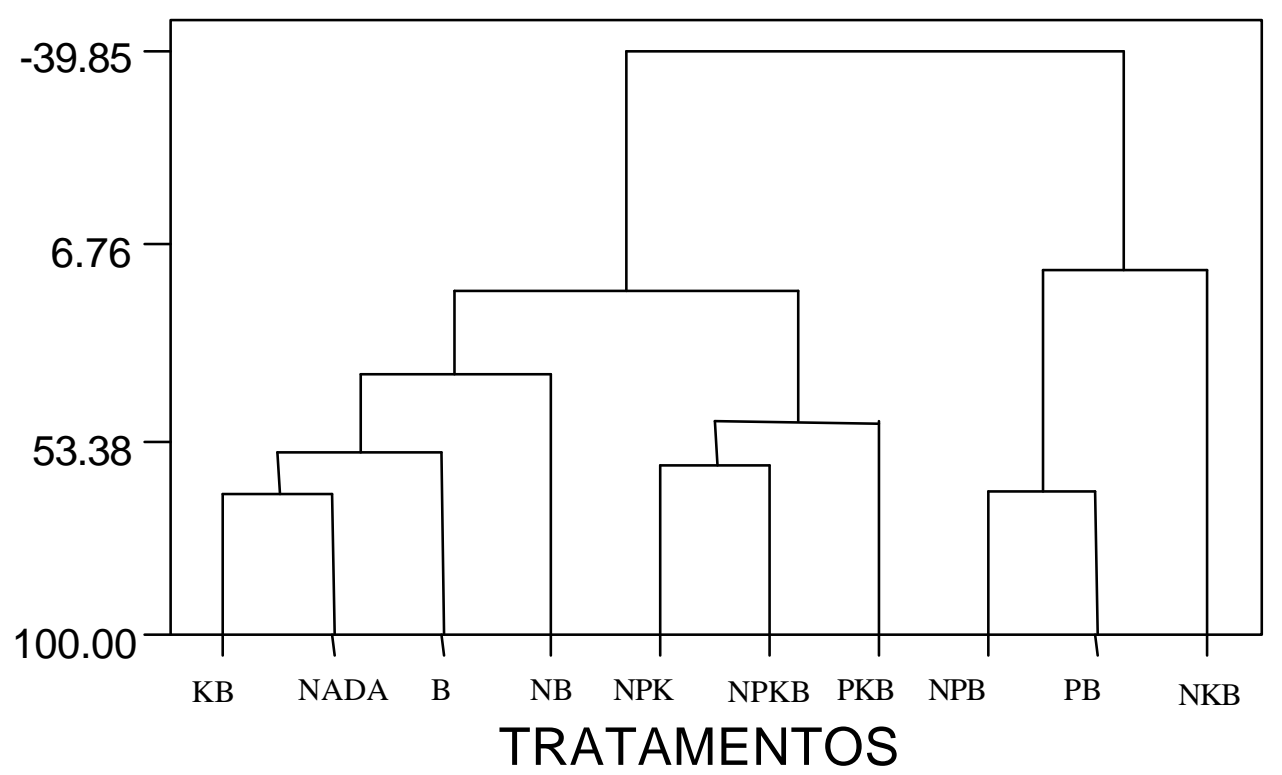

Figura 18 - Agrupamento dos tratamentos segundo os dados dendrométricos.

Juntando-se os dados dos teores de nitrogênio (N), fósforo (P), potássio (K) e boro (B) nas folhas com os dados dendrométricos observamos que os agrupamentos tornam-se semelhantes aos encontrados no agrupamento dos teores de nutrientes, mostrando que existiu uma tendência do teor de nutrientes influir no crescimento das plantas, conforme apresentado na Figura 19. 


\section{Similaridade}

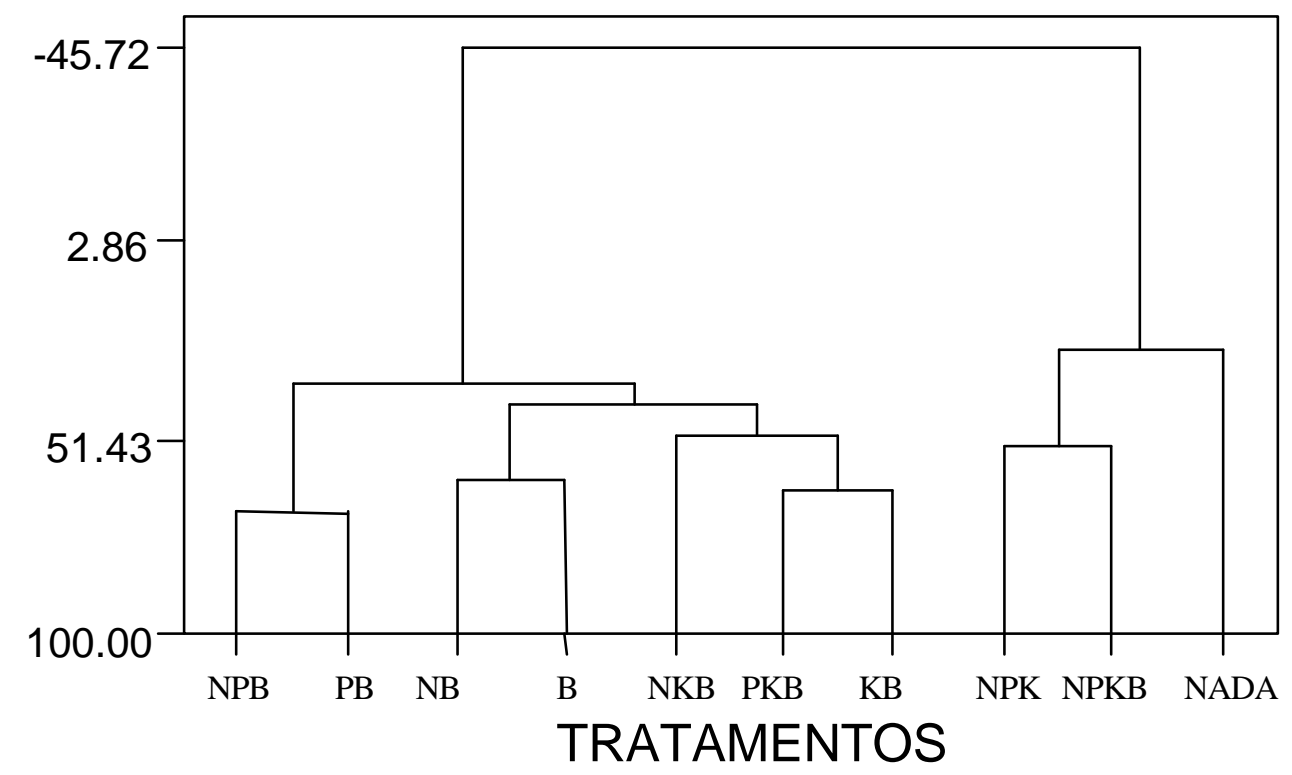

Figura 19 - Agrupamento dos tratamentos segundo os dados dendrométricos e de nitrogênio (N), fósforo (P), potássio (K) e boro (B).

\subsection{Análises das imagens}

Para a análise das imagens foram utilizados os valores da estatística de pixel obtidos pelo software ENVI 2.6, que são apresentados na forma de valores entre 0 e 255.

Estes valores obtidos, para cada uma das regiões de interesse relativas às repetições dos tratamentos com omissões de nitrogênio (N), fósforo (P), potássio (K) e boro (B), nas duas altitudes de vôo $(1500 \mathrm{~m}$ e $3000 \mathrm{~m})$, são apresentados como valores médios (MED), máximos (MAX), mínimos (MIN) e desvio padrão (DESPAD), obtidos tanto para a câmera COHU (CO), quanto para a PANASONIC (PA) nas faixas do espectro eletromagnético estudadas. 


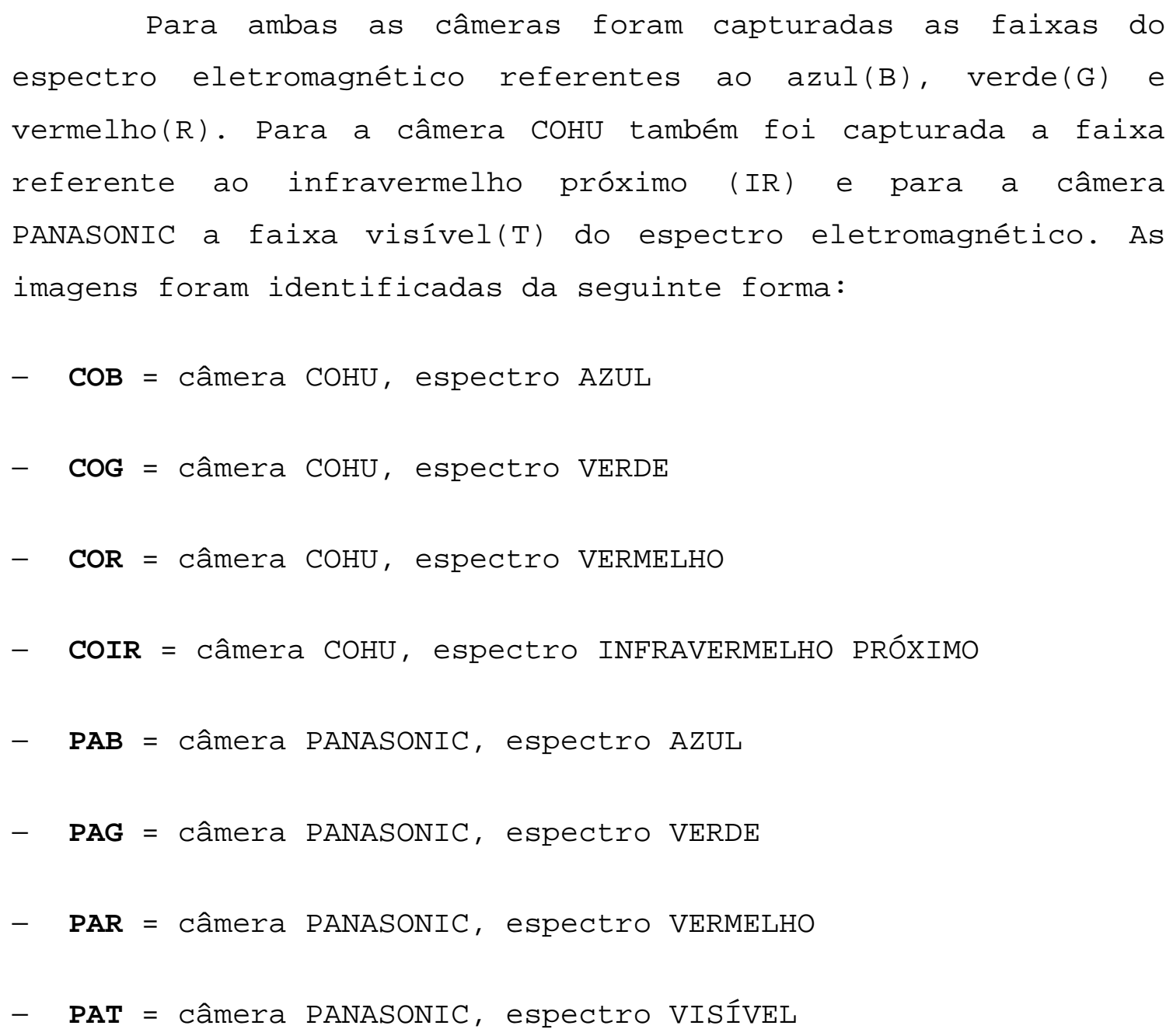


espacial, reduzindo as diferenças entre os valores obtidos para cada região de interesse.

Tabela 11. Agrupamentos das imagens obtidas conforme os dados da estatística de pixel.

\begin{tabular}{ccc}
\hline & 1500 m & \\
VARIÁVEL & GRUPO 1 & GRUPO 2 \\
\hline MÍN & COG COR PAB COB & COIR PAG PAT PAR \\
MÁX & COG COR PAB PAR PAT PAG & COB COIR \\
MÉD & COG COR PAB COB COIR PAR & PAT PAG \\
DESPAD & COG COIR COB PAR PAT & PAG PAB COR \\
\hline VARIÁVEL & 3000 m & \\
\hline MÍN & COB COG PAB COR & COIR PAR PAT PAG \\
MÁX & COB COG PAB COR & COIR PAR PAT PAG \\
MÉD & COB COG PAB COR & COIR PAR PAT PAG \\
DESPAD & COB COG PAB COIR PAT & COR PAR PAG \\
\hline
\end{tabular}

COB = câmera COHU, espectro AZUL; COG = câmera COHU, espectro VERDE; COR = câmera COHU, espectro VERMELHO; COIR = câmera COHU, espectro INFRAVERMELHO PRÓXIMO; $\mathbf{P A B}=$ câmera PANASONIC, espectro AZUL; PAG = câmera PANASONIC, espectro VERDE; PAR = câmera PANASONIC, espectro VERMELHO; PAT = câmera PANASONIC, espectro VISÍVEL.

$\mathrm{Na}$ altitude de $1500 \mathrm{~m}$, obteve-se assim como na altitude de 3000 m, dois grupos de imagens para cada uma das variáveis, porém, sem a formação de grupos semelhantes, demonstrando que as imagens (espectros obtidos com cada câmera) comportaram-se de maneira diferente na sensibilidade aos tratamentos (Tabela 11) . 


\begin{abstract}
Isto indicou que as imagens obtidas a $1500 \mathrm{~m}$ apresentaram melhores resultados quanto à resposta das câmeras na determinação das deficiências nutricionais.
\end{abstract}

\begin{abstract}
Assim como as imagens foram agrupadas utilizando os valores obtidos na estatística de pixel para $1500 \mathrm{~m}$ e $3000 \mathrm{~m}$, os tratamentos foram agrupados conforme estes mesmos valores, a fim de verificar se existia relação com a omissão nutrientes e o crescimento das plantas na formação dos grupos (Tabela 12).
\end{abstract}

Os agrupamentos obtidos foram comparados aos
agrupamentos de tratamentos conforme os teores dos nutrientes (N, P, K e B), apresentados na Figura 17, e os agrupamentos obtidos conforme os dados dendrométricos (Figura 18).

Os agrupamentos obtidos através dos valores da
estatística de pixel das imagens mostraram-se semelhantes ao
agrupamento dos dados dendrométricos, sendo que entre as
variáveis MIN, MAX, MED e DESPAD, os valores mínimos (MIN) e os
valores médios (MED) da estatística de pixel das imagens
obtidas a $1500 \mathrm{~m}$ foram os que mais se aproximaram do
agrupamento dos tratamentos através dos dados dendrométricos.
capturadas a $1500 \mathrm{~m}$ de altitude têm melhor relação com os dados
dendrométricos do que com os teores nutricionais das plantas
dos tratamentos.


Tabela 12. Agrupamentos dos tratamentos de omissão de nutrientes conforme os valores obtidos na estatística de pixel.

\begin{tabular}{|c|c|c|}
\hline & $1500 \mathrm{~m}$ & \\
\hline VARIÁVEL & GRUPO 1 & GRUPO 2 \\
\hline MÍN & $\begin{array}{c}\text { NPKB PKB NPB PB } \\
\text { NPK NKB }\end{array}$ & KB NB B NADA \\
\hline MÁX & NPKB PKB NPB PB & KB NB B NADA NKB NPK \\
\hline MÉD & NPKB PKB NPB PB NPK & $\mathrm{KB} N \mathrm{NB} B \mathrm{NADA} N \mathrm{NKB}$ \\
\hline DESPAD & $\begin{array}{c}\text { NPKB NKB NB NADA } \\
\mathbf{3 0 0 0} \mathbf{~ m} \\
\end{array}$ & KB B NPK PKB NPB PB \\
\hline VARIÁVEL & GRUPO 1 & GRUPO 2 \\
\hline MíN & NPKB B NADA & $\begin{array}{c}\text { NPK PKB NKB NB NPB } \\
\text { PB KB }\end{array}$ \\
\hline MÁX & NPKB B NADA NB & $\begin{array}{cl}\mathrm{NPB} & \mathrm{NPK} \\
& \mathrm{NKB} \mathrm{PKB} K \mathrm{~KB}\end{array}$ \\
\hline MÉD & NPKB NPB NPK NKB PKB & $B$ NADA NB KB PB \\
\hline DESPAD & $\mathrm{NPB} \quad \mathrm{NB} \quad \mathrm{PB}$ & $\begin{array}{c}\text { NKB B NPK NPKB PKB } \\
\text { KB NADA }\end{array}$ \\
\hline
\end{tabular}

MIN = valores mínimos dos pixels na imagem; $\mathbf{M A X}=$ valores máximos dos pixels na imagem; MED = valores médios dos pixels na imagem; DESPAD = desvio padrão da média dos valores dos pixels na imagem.

Foram feitas análises de regressão para encontrar modelos lineares com coeficientes de correlação significativos que explicassem o comportamento dos dados da estatística de pixel de cada imagem, e suas relações com produtividade e teor de nutrientes nas folhas, confirmando assim os resultados obtidos nas análises de agrupamentos. 
Para isto os dados das imagens foram reordenados e divididos por faixa do espectro eletromagnético (VERMELHO, AZUL E VERDE) .

Foram encontradas relações significativas entre os dados dendrométricos e os valores da estatística de pixel apenas para algumas imagens obtidas a $1500 \mathrm{~m}$ (Tabela 13).

Para as imagens obtidas aos $3000 \mathrm{~m}$ de altitude não foi encontrada nenhuma relação significativa entre os dados das imagens e os parâmetros dendrométricos ou teores de nutrientes nas plantas.

Apesar das relações entre os dados da estatística de pixel das imagens obtidas a $3000 \mathrm{~m}$ de altitude e os dados dendrométricos não apresentarem coeficientes de correlação significativos, qualitativamente é possível distinguir os tratamentos tão bem quanto nas imagens obtidas a $1500 \mathrm{~m}$, mostrando que os valores de pixel podem estar "mascarados" pela menor resolução espacial.

Isto indica que a utilização de câmeras de vídeo com maior resolução espacial, pode promover análises mais apuradas da situação de plantios de eucalipto, diferenciando o dossel de forma qualitativa. 
Tabela 13. Relações significativas entre os parâmetros dendrométricos e os dados das imagens.

\begin{tabular}{|c|c|c|c|c|c|}
\hline ESPECTRO & $\begin{array}{l}\text { VARIÁVEL } \\
\text { DEPENDENTE }\end{array}$ & $\begin{array}{c}\text { VARIÁVEL } \\
\text { INDEPENDENTE }\end{array}$ & $\mathrm{R}^{2}$ & $\mathrm{~F}$ & $\operatorname{Pr}>\mathrm{F}$ \\
\hline \multicolumn{6}{|c|}{$\begin{array}{l}\text { Imagem do espectro azul da câmera COHU (COB) } \\
\qquad 1500 \mathrm{~m}\end{array}$} \\
\hline \multirow{3}{*}{ VERMELHO } & DAP & MIN & 0,5527 & 16,68 & 0,0001 \\
\hline & ALT & MIN & 0,5285 & 31,39 & 0,0001 \\
\hline & $\mathrm{ACOPA}$ & MIN & 0,5472 & 18,19 & 0,0001 \\
\hline \multirow{2}{*}{ VERDE } & $\mathrm{DAP}$ & MAX & 0,6328 & 14,93 & 0,0001 \\
\hline & $\mathrm{ALT}$ & MED & 0,6224 & 22,25 & 0,0001 \\
\hline \multirow{3}{*}{ AZUL } & DAP & MED & 0,5961 & 19,92 & 0,0001 \\
\hline & $\mathrm{ALT}$ & MED & 0,6184 & 21,87 & 0,0001 \\
\hline & $\mathrm{ACOPA}$ & DESPAD & 0,5393 & 35,82 & 0,0001 \\
\hline \multicolumn{3}{|c|}{ Imagem do espectro inf } & câmera CC & $\mathrm{HU} \quad(\mathrm{CO}$ & 2) $1500 \mathrm{~m}$ \\
\hline & $\mathrm{DAP}$ & MIN & 0,5328 & 15,39 & 0,0001 \\
\hline \multirow[t]{3}{*}{ VERMELHO } & ALT & MIN & 0,6452 & 14,68 & 0,0001 \\
\hline & $\mathrm{ACOPA}$ & MIN & 0,5172 & 11,28 & 0,0001 \\
\hline & $\mathrm{DAP}$ & MIN & 0,6774 & 20,64 & 0,0001 \\
\hline \multirow[t]{3}{*}{ VERDE } & ALT & MIN & 0,6937 & 19,63 & 0,0001 \\
\hline & $\mathrm{ACOPA}$ & MIN & 0,6442 & 12,36 & 0,0001 \\
\hline & $\mathrm{DAP}$ & MIN & 0,5746 & 11,70 & 0,0001 \\
\hline \multirow[t]{2}{*}{ AZUL } & $\mathrm{ALT}$ & MIN & 0,6360 & 18,38 & 0,0001 \\
\hline & $\mathrm{ACOPA}$ & MED & 0,5173 & 11,41 & 0,0001 \\
\hline Imagem & espectro ve & $\begin{array}{l}\text { melho da câme } \\
1500 \mathrm{~m}\end{array}$ & La PANAS & ONIC & AR) \\
\hline VERMELHO & DAP & DESPAD & 0,5313 & 31,74 & 0,0001 \\
\hline AZUL & $\mathrm{DAP}$ & DESPAD & 0,5288 & 15,15 & 0,0001 \\
\hline
\end{tabular}

MIN = valores mínimos dos pixels na imagem; MAX = valores máximos dos pixels na imagem; MED = valores médios dos pixels na imagem; DESPAD = desvio padrão da média dos valores dos pixels na imagem; DAP = diâmetro do caule a 1,3 m do solo; ALT = altura total da planta; ACOPA = área da copa das plantas. 
Ganhos expressivos podem ser obtidos com a eliminação da transformação das imagens do formato analógico (S-VHS) para o digital, eliminando a captura das imagens por meio de placas eletrônicas, que proporcionam expressiva perda de qualidade e alteração dos valores de pixel.

Índices de vegetação calculados através dos valores da imagem podem ser um método de análise eficiente para avaliação de características de plantios de eucalipto, porém, exigem que as diferentes faixas do espectro eletromagnético sejam referenciadas, de forma a obter os valores de cada uma delas para o mesmo elemento de pixel. 


\section{CONCLUSÕES}

1. As imagens $\mathrm{COB}$ (imagem do espectro azul da câmera COHU), COIR (imagem do espectro infravermelho próximo da câmera COHU) e PAR (imagem do espectro vermelho da câmera PANASONIC), obtidas a $1500 \mathrm{~m}$ de altitude obtiveram relações entre os dados dendrométricos e os valores de pixel;

2. Os valores de pixel das imagens capturadas tiveram relação apenas com os dados dendrométricos. Isto mostra que as deficiências nutricionais foram detectadas de maneira indireta, pois afetaram significativamente o crescimento das plantas;

3. A altitude de vôo influenciou os valores de pixel das imagens capturadas com ambas as câmeras;

4. A câmera COHU, que é apta a capturar a faixa do infravermelho próximo do espectro eletromagnético, obteve mais relações significativas com os dados dendrométricos do que a câmera PANASONIC;

5. A análise de Cluster mostrou-se uma boa ferramenta para avaliar os dados;

6. As imagens de vídeo são uma ferramenta potencial para avaliações quantitativas e qualitativas de plantios de 
eucalipto devido a sua praticidade e baixo custo, além de proporcionar a avaliação imediata para tomada de decisões e a possibilidade de elaboração de mapas temáticos;

7. Melhorias no sistema de captura podem ser promovidas com a utilização de câmeras digitais, eliminando a transformação das imagens do meio analógico (fita magnética) para o meio digital;

8. A captura e separação digital das faixas do espectro de uma mesma imagem podem proporcionar uma análise dos valores de pixel mais precisa, e viabilizaria a obtenção de índices de vegetação. 


\section{REFERÊNCIAS BIBLIOGRÁFICAS}

AIDAR, M.P.M. Ecologia do Araribá (Centrolobium tomentosum Guill. ex. Benth., Fabaceae) e o ecótono mata ciliar da bacia do rio Jacaré- Pepira, São Paulo. Campinas, 1992. 99p. Dissertação (Mestrado) - Instituto de Biologia, Universidade Estadual de Campinas.

ANDA/POTAFOS. Manual de fertilidade do solo. São Paulo: 1989. $153 \mathrm{p}$.

BARROS, N. F. Relação solo-eucalipto. Viçosa: Editora Folha de Viçosa, 1990. 330p.

COUTO, H.T.Z.; VETTORAZZI, C.A.; FERRAZ, S.F. de B.; POMPERMAYER NETO, P. Airborne videography as a data source for the decision-making process in agriculture. In: INTERNATIONAL CONFERENCE ON GEOSPATIAL INFORMATION IN AGRICULTURE AND FORESTRY, 2., Lake Buena Vista, 2000. Proceedings. Lake Buena Vista: ERIM, 2000. p.459-461. 
DELL, B.; MALAJACZUK, N.; GROVE, T.S. Nutrient disorders in plantation eucalypts. Camberra: Australian Centre for International Agricultural Research, 1995. 104p.

EL-HAKIM, S. F. Real time image metrology UIT CCD cameras. Photogrammetric Engeneering and Remote Sensing, V.52, n.11, p.1757-1766, 1986.

ENVI. User's guide: version 2.6. Colorado, 1997. 590p.

EPSTEIN, E. Nutrição mineral das plantas: princípios e perspectivas; Tradução e notas de E. Malavolta. São Paulo: Ed. da Universidade de São Paulo. 1975. 344 p.

EVERITT, J.H.; ESCOBAR, D.E. Using video imaging technology for remote sensing of natural resources. In: SIMPOSIO LATINOAMERICANO DE PERCEPCION REMOTA - Latinoamérica evaluada desde el espacio, Puerto Vallarta, 1996b. Memórias. Puerto Vallarta: FELPER, 1996b. p. 753-773.

EVERITT, J.H.; NIXON, P.R. Video imagery: a new remote sensing tool for range management. Journal of Range Management, v.38, p.421-424, 1985 .

EVERITT, J.H.; ESCOBAR, D.E.; DAVIS, M.R. Mid infrared video: a possible tool for termal analysis of wildfires. Geocarto international, v.4, p.39-45, 1989 b. 
EVERITT, J.H.; ESCOBAR， D.E.; JUDD, F.W. Evaluation of airborne video imagery for distinguishing Black Mangrove (Avicennia germinans) on the lower Texas gulf coast. Journal of Coastal Research, v.7, p.1169-1173, 1991c.

EVERITT, J.H.; ESCOBAR, D.E.; NORIEGA, J.A. High resolution multispectral video system. Geocarto International, V.6, n.4, p.45-51, 1991b.

EVERITT, J.H.; ESCOBAR, D.E.; VILLARREAL, R. Evaluation of single band video and video band based indices for grassland phytomass assessment. Photogrammetric Engeneering and Remote Sensing, v.54, p.1177-1180, 1988a.

EVERITT, J.H.; ESCOBAR, D.E.; ALANIZ, M.A.; DAVIS, M.R. Using airborne middle infrared $(1,45-20 \mathrm{~nm})$ video imagery for distinguishing plant species and soil conditions. Remote Sensing of Environment, v.22, p.423-428, 1987.

EVERITT, J.H.; ESCOBAR, D.E.; ALANIZ, M.A.; DAVIS, M.R. Using multispectral video imagery for detecting soil surface conditions. Photogrammetric Engeneering and Remote Sensing, v. 55, n. 4, p. 467-471, 1989a.

EVERITT, J.H.; ESCOBAR, D.E.; ALANIZ, M.A.; DAVIS, M.R. Light reflectance characteristics and video remote sensing of pricklypear. Journal of Range Management, v.44, p.587-592, $1991 d$. 
EVERITT, J.H.; ESCOBAR, D.E.; CAVAZOS, I; NORIEGA, J.R.; DAVIS, M.R. A three camera multispectral digital video imaging system. Remote Sensing of Environment, v.54, p.333-337, 1995.

EVERITT, J.H.; ESCOBAR, D.E.; DAVIS, M.R.; JUDD, F.W. Integration of airborne videography, GPS and GIS technologies for mapping plant species and inset infestations. In: INTERNATIONAL AIRBORNE REMOTE SENSING CONFERENCE AND EXHIBITION, 2., San Francisco, 1996 . Proceedings. San Francisco: ERIM, 1996a. p.239-258.

EVERITT, J.H.; ESCOBAR, D.E.; GERBERMANN, A.H.; ALANIZ, M.A Detecting saline soils with video imagery. Photogrammetric Engeneering and Remote Sensing, v. 54, p.1283-1287, 1988b.

EVERITT, J.H.; ESCOBAR, D.E.; NORIEGA, J.R.; DAVIS, M.R. Description and application of a video system that simulates TM LANDSAT 5, 4, 3 imagery. In: INTERNATIONAL CONFERENCE ON GEOSPATIAL INFORMATION IN AGRICULTURE AND FORESTRY, 1., Lake Buena Vista, 1998. Proceedings. Lake Buena Vista: ERIM, 1998. p. 315-326.

EVERITT, J.H.; ESCOBAR, D.E.; SUMMY, M.A.; DAVIS, M.R. Using airborne video, global positioning system, and geographical information system technologies for detecting and mapping citrus blackfly infestations. Southwestern Entomologist, v.19, p.129-138, 1994 . 
EVERITT, J.H.; ESCOBAR, D.E.; VILLAREAL, R.; NORIEGA, J.R.; DAVIS, M.R. Airborne video systems for agricultural assessment. Remote Sensing of Environment, v.35, p.231-242, 1991 .

EVERITT, J.H.; LULLA, K.; ESCOBAR, D.E.; RICHARDSON, A.J. Aeroespace video imaging system for rangeland management. Photogrammetric Engeneering and Remote Sensing, v.56, n.3, p.343-349, 1990 .

EVERITT, J.H.; ESCOBAR, D.E.; BLAZQUEZ, C.H.; HUSSEY, M.A.; NIXON, P.R. Evaluation of the mid infrared (1.45 to $2.0 \mathrm{~nm}$ ) with a black and white infrared video camera. Photogrammetric Engeneering and Remote Sensing, V.52, p.1655-1660, 1986a.

GAUSMAN, H.W.; ESCOBAR, D.E.; BOWEN, R.L. A video system to demonstrate interactions of near infrared radiation with plant leaves. Remote Sensing of Environment. v.13, p.363366,1983 .

HAIR, J.F. Multivariate data analysis. 4. Ed. Washington: Library of Congress, 1998. 519p.

HART, W.G.; EVERITT, J.H.; ESCOBAR, D.E.; DAVIS, M.R.; GARZA, M.G. Comparing imaging systems for assessment of diverse conditions of agricultural resources. In: WORKSHOP ON VIDEOGRAPHY, 1., Falls Church, 1998. Proceedings. Falls Church: ASPRS, 1988. p.160-165. 
KING, D. J. Airborne multiespectral digital camera and video sensors: a critical review of system designs and applications. Canadian Journal of Remote Sensing, v.21, n . 3, p. 245-273, 1995 .

LINDEN, D.S. Videography for foresters. Journal of Forestry. v.98, n.6, p.25-28. 2000 .

LOWE, J.L.; OSWALD, B.P.; COLEMAN, T.L.; TADESSE, W.; EVERITT, J.H.; ESCOBAR, D.E.; DAVIS, M.R. Comparison of conventional ground sampling and remote sensing techniques for mapping forest vegetation. USDA Capacity Building Grants Program e USDA-CSREES, p.31-52, 1995.

LUSCH, D.P. Super VHS for improved airborne CIR videography. In: WORKSHOP ON VIDEOGRAPHY, 1., Terre Haute, 1988. Proceedings. Terre Haute: ASPRS, 1988. p.23- 29 .

MALAVOLTA, E.; VITTI, G.C.; OLIVEIRA, S.A. Avaliação do estado nutricional das plantas: princípios e aplicações Piracicaba: POTAFOS, 1997. 319p.

MAUSEL, P.W.; EVERITT, J.H.; ESCOBAR, D.E.; KING, D.J. Airborne videography: current status and future perspectives. Photogrammetric Engineering and Remote Sensing, V.58, n. 8, p.1189-1195, 1992. 
MAUSEL, P.W.; KALALIKA, G.; EVERITT, J.H.; ESCOBAR, D.E. Delineation of soil series subareas using multiespectral video in relation to rural tax assessment. In: BIENNIAL WORKSHOP ON COLOR AERIAL PHOTOGRAPHY AND VIDEOGRAPHY FOR RESOUSE MONITORING, 14., Logan, 1993. Proceedings. Logan: ASPRS, 1993. p.82 - 95 .

NIXON, P.R.; ESCOBAR, D.E.; MENGES, R.M. A multiband video system for quick assessment of vegetal condition and discrimination of plant species. Remote sensing of Environment, V.17, p.203-208, 1985.

NIXON, PR., ESCOBAR, D.E and BOWEN, R.L. A multi video false color imaging system for remote sensing applications. In: BIENNIAL WORKSHOP ON COLOR AERIAL PHOTOGRAPHY AND VIDEOGRAPHY IN THE PLANT SCIENCES, 11., Falls Church, 1997. Proceedings. Falls Church: ASPRS, 1987. p.295-305.

PONZONI, F.J.; GONÇALVES, J.L.M. Avaliação do uso de dados TM/Landsat na identificação de plantios de Eucaliptus spp. deficientes em potássio. Revista Árvore, v.21, n.3, p.421 $431,1997$.

PONZONI, F.J.; GONÇALVES, J.L.M. Spectral features associated with nitrogen, phosphorus and potassium deficiencies in Eucaliptus saligna seedling leaves. International Journal of Remote Sensing, v.20, n.11, p. 2249 - 2264, 1999. 
RICHARDSON, A.J.; MENGES, R.M.; E NIXON, P.R. Distinguishing weed from crop plants using video remote sensing. Photogrammetric Engineering and Remote sensing, V.52, p. 1785-1790, 1985 .

RICHARDSON, A.J.; HEILMAN, M.D.; ESCOBAR, D.E. Estimating grain sorghum yield from video and reflectance based PVI measurements at peak canopy development. Journal of Imaging Technology. v.16, n.3, p.104-109, 1990.

SAS INSTITUTE. SAS/ETS User's guide: version 6. 2. ed., Cary, 1993. 1022p.

SCHLEMMER, M.R.; FRACIS, D.D. Monitoring above ground biomass with multi spectral airborne imagery. In: INTERNATIONAL CONFERENCE ON GEOSPATIAL INFORMATION IN AGRICULTURE AND FORESTRY, 1., Lake Buena Vista, 1998. Proceedings. Lake Buena Vista: ERIM, 1998. v.2, p.581-568.

SHIMABUKURO, M.T. Avaliação de classificadores espectrais de imagens TM LANDSAT em áreas rurais densamente ocupadas - o caso da região de Brotas e Torrinha, São Paulo, Brasil. Campinas, 1996. 177p. Dissertação (Mestrado) - Instituto de Biologia, Universidade Estadual de Campinas.

SILVEIRA, R.L.V.A.; GONÇALVES, A.N.; GONÇALVES, J.L.M.; BRANCO, E.F. Levantamento e estudo do mercado de fertilizantes em florestas brasileiras. Relatório Interno. Piracicaba, SP: IPEF, $1995 . \quad 117 \mathrm{p}$. 
SILVEIRA, R.L.V.A. Crescimento e estado nutricional de Eucalyptus citriodora cultivado sob doses de boro e sua relação com a agressividade de Botryosphaeria ribis. Piracicaba, 1996. 97p. Dissertação (Mestrado) - Escola Superior de Agricultura "Luiz de Queiroz", Universidade de São Paulo.

UM, J.S.; WRIGHT, R. The analog to digital transition and implications for operational use of airborne videography. Photogrammetric Engineering \& Remote Sensing. v. 65, n.3. p.269-275. 1999.

VALENTINI, J.L.; PERES-NETO, P.R.; FERNANDES, F.A.S. Oecologia Brasiliensis. Rio de Janeiro: UFRJ, Instituto de Biologia, 1995. v.2, p. 27-55: Tópicos em tratamento de dados biológicos.

YANG, C.; ANDERSON, G.L. Determining within-field management zones for grain sorghum using aerial videography. In: INTERNATIONAL SYMPOSIUM ON REMOTE SENSING OF ENVIRONMENT, 26., Vancouver, 1996. Proceedings. Vancouver: ASPRS, 1996. p. 606-611.

YANG, C.; ANDERSON, G.L. Identifying spatial plant growth variability in grain sorghum using aerial videography. In: BIENNIAL WORKSHOP ON COLOR PHOTOGRAPHY AND VIDEOGRAPHY IN RESOURCE ASSESSMENT, 16., Falls Church, 1997. Proceedings. Falls Church: ASPRS, 1997. p.443-450. 
YANG, C.; ANDERSON, G.L.; EVERITT, J.H.; ESCOBAR, D.E. Mapping plant growth and yield variations from aerial digital videography. In: INTERNATIONAL CONFERENCE ON GEOSPATIAL INFORMATION IN AGRICULTURE AND FORESTRY, 1., Lake Buena Vista, 1998. Proceedings. Lake Buena Vista: ERIM, 1998. v.2, p.577-586.

WIEGAND, C.L.; EVERITT, J.H.; RICHARDSON, A.J. Comparison of multispectral video and SPOT-1 HRV observations for cotton affected by soil salinity. Remote Sensing of Environment, v.13, n. 8, p.1511-1525, 1992 .

WIEGAND, C.L.; RHOADES, J.D.; ESCOBAR, D.E.; EVERITT, J.H. Photographic and videographic observations for determining and mapping the response of cotton to soil salinity. Remote Sensing of Environment, v.49, p.212-223, 1994. 